OPEN ACCESS

Edited by:

Vijai Kumar Gupta,

National University of Ireland, Galway,

Ireland

Reviewed by:

Jun-Jie Zhang,

Indiana University School of Medicine,

USA

Martin Siemann-Herzberg,

University Stuttgart, Germany

*Correspondence:

Alok Adholeya

aloka@teri.res.in;

adholeya1@gmail.com

Specialty section:

This article was submitted to Microbiotechnology, Ecotoxicology and Bioremediation,

a section of the journal

Frontiers in Microbiology

Received: 30 December 2015 Accepted: 04 April 2016 Published: 03 May 2016

Citation: Minhas AK, Hodgson P, Barrow CJ and Adholeya A (2016) A Review on the Assessment of Stress Conditions

for Simultaneous Production of Microalgal Lipids and Carotenoids.

Front. Microbiol. 7:546.

doi: 10.3389/fmicb.2016.00546

\section{A Review on the Assessment of Stress Conditions for Simultaneous Production of Microalgal Lipids and Carotenoids}

\author{
Amritpreet K. Minhas ${ }^{1}$, Peter Hodgson ${ }^{2}$, Colin J. Barrow ${ }^{3}$ and Alok Adholeya ${ }^{1 *}$ \\ ${ }^{1}$ Biotechnology and Bioresources Division, TERI-Deakin Nanobiotechnology Centre, The Energy and Resources Institute, \\ India Habitat Centre, New Delhi, India, ${ }^{2}$ Institute for Frontier Materials, Deakin University, Victoria, VIC, Australia, ${ }^{3}$ School of \\ Life and Environmental Sciences, Deakin University, Victoria, VIC, Australia
}

Microalgal species are potential resource of both biofuels and high-value metabolites, and their production is growth dependent. Growth parameters can be screened for the selection of novel microalgal species that produce molecules of interest. In this context our review confirms that, autotrophic and heterotrophic organisms have demonstrated a dual potential, namely the ability to produce lipids as well as value-added products (particularly carotenoids) under influence of various physico-chemical stresses on microalgae. Some species of microalgae can synthesize, besides some pigments, very-long-chain polyunsaturated fatty acids (VL-PUFA, > 20C) such as docosahexaenoic acid and eicosapentaenoic acid, those have significant applications in food and health. Producing value-added by-products in addition to biofuels, fatty acid methyl esters (FAME), and lipids has the potential to improve microalgae-based biorefineries by employing either the autotrophic or the heterotrophic mode, which could be an offshoot of biotechnology. The review considers the potential of microalgae to produce a range of products and indicates future directions for developing suitable criteria for choosing novel isolates through bioprospecting large gene pool of microalga obtained from various habitats and climatic conditions.

\section{Keywords: carotenoids, PUFA, autotrophic, heterotrophic, lipids, biorefinery}

\section{INTRODUCTION}

Microalgae are autotrophic organism that consumes light energy and inorganic nutrients and produces biomass rich in value-added products such as lipids, carbohydrates, proteins, and pigments (Markou and Nerantzis, 2013). Highly explored for lipids, microalgae also produce metabolites such as carotenoids (lutein, zeaxanthin, and astaxanthin), long-chain polyunsaturated fatty acids (LC-PUFA), and vitamins (Pal et al., 2011), that are widely used in nutraceuticals industries as food additives (Priyadarshani and Rath, 2012). The interest for large scale cultivation of microalgal biomass that are rich reserves of high value metabolites is increasing, however detailed literature on its optimal and economically more sustainable production is not available (Clarens et al., 2010; Norsker et al., 2011; Soratana and Landis, 2011).

The production of lipids, carotenoids and algal biomass can be enhanced under environmental stress factors (Mata et al., 2010; Mulders et al., 2014; González et al., 2015). In addition to stress 
factors, selection and use of microalgal species and strains is also important for enhancing the metabolite production. Therefore, exploration of a wider and more diverse gene pool of microalgae is required. For economical production, deriving multiple products such as lipids and high-value by-products from the same biomass in one growth cycle is one way (Campenni et al., 2013; Nobre et al., 2013). Further optimizing culture conditions, by selecting organisms that can overcome the limitations imposed by ambient conditions, and by selecting strains that produce high lipid content can also lower the unit cost of microalgae-based biofuels (Wijffels et al., 2010).

Current research on microalgae based production is focused on developing autotrophic or heterotrophic cultivation strategies most conducive for production of lipids and other valueadded products in laboratory-scale biorefineries. The present article provides a review on the cultivation strategies used for microalgae growth, mainly focusing on the environmental stress factors, for increasing the production of lipids and value-added products (namely, lutein, astaxanthin, and $\beta$-carotene). We provide information on developing methods that can maximize the production of biofuel, biomass, and other value-added byproducts (carotenoids) from the same species or strains of microalgae that will become a win-win strategy in the coming decades. Some of these phenomenons are covered in this review, however for details on other metabolites such as phycobilins, polysaccharides and vitamins see review of Skjånes et al. (2013) and Markou and Nerantzis (2013).

\section{MICROALGAL LIPID SYNTHESIS}

Microalgal lipids are divided in to two main categories, namely those-used as biofuel (with 14-20 carbon chains) and as food (containing 20 carbon chains; Jacob-Lopes et al., 2015). Green algae share their ancestry with higher plants and their metabolic mechanisms and photosynthetic pigments are similar to those found in higher plants (Yu et al., 2011). Some microalgae also produce large amounts of lipids in the form of triacylglycerides (TAGs). The synthesis of lipids in microalgae varies with the species (from either freshwater or marine habitats or in cyanobacteria) used ( $\mathrm{Hu}$ et al., 2008). Compared to cyanobacteria, two unique features of algae are the ability to store large quantities of lipids in the form of oil globules in parts of the cell other than chloroplasts and the ability to link the electron transport system to hydrogen production (Radakovits et al., 2010). Li et al. (2012) showed that accumulation of neutral lipids in the cell occurs through the conversion of either starch or carbon to lipids, but conversion depends on microalgal strains, different strains have different mechanism for transmitting the carbon flux from the carbohydrate pathway for synthesizing lipids.

In unicellular organisms, lipid biosynthesis follows a complex pathway where synthesis initiates with the formation of acetyl CoA by the ACCase gene through acetyl CoA carboxylation. This is the key step at which carbon is assigned for lipid synthesis ( $\mathrm{Hu}$ et al., 2008), as shown in Figure 1 (adapted and modified from Perez-Garcia et al., 2011). Lipid biosynthesis has been explored most extensively in Chlamydomonas reinhardtii (Moellering and Benning, 2010). The first metabolic study for increasing the accumulation of FAs was reported in Cyclotella cryptica, in which the acetyl-CoA carboxylase gene (ACCase) was overexpressed (Dunahay et al., 1996). Some microalgae adapt well to various environmental conditions that affect cellular processes including lipid metabolism (Juneja et al., 2013). Microalgae are also known to synthesize very -long-chain polyunsaturated FAs (VLPUFA, $>20 \mathrm{C}$ ), and the synthesis is regulated by desaturases and elongases, which are temperature-sensitive enzymes (Niu et al., 2013).

Polyunsaturated fatty acids (PUFA) are mainly found in fish originate from digested microalgae in the marine environment. Moreover, eicosapentaenoic acid (EPA) and docosahexaenoic acid (DHA) are the most valuable FAs found in microalgae and, their high content found in microalgae is rich in these two FAs (Spolaore et al., 2006; Yen et al., 2013), make it suitable for biofuel manufacturing (Gimpel et al., 2015). Under abiotic forms of stress, many microalgae produce TAGs that can serve as feedstock for biofuel production. However, the amounts of TAGs vary with the species and the genera (Trentacoste et al., 2013). Various stress factors induce changes in the metabolic activities of a cell such as activation of starch and accumulation of TAGs leading to accumulation of lipid bodies in algae (Johnson and Alric, 2013). Since lipid biosynthesis is a complex process, it not only presents greater challenges in increasing the production of specific lipids but also in increasing overall lipid production in microalgae. It is therefore important to increase the application of metabolic engineering to lipid biosynthesis.

\section{STRATEGIES TO ENHANCE STRESS BASED LIPIDS CHANGES IN MICROALGAE}

Autotrophic and heterotrophic strategies have been studied widely, and several physicochemical stress factors that affect the metabolism of microalgae significantly have been identified. Managing environmental stress is a typical approach used in refining microalgae based lipid production in the laboratory and at the pilot-scale. The most common stress factors used for enhancing lipid production are light intensity, temperature, and nitrates (Figure 2).

\section{Autotrophic Growth Factors Temperature}

Temperature is a stress factor that greatly influences the rate of growth, net lipid productivity and FA profiles in a wide range of microalgal species (Ho et al., 2014a). As microalgal growth and secondary metabolic pathway vary with temperature (James et al., 2013), greater knowledge of the biochemical response to temperature may yield useful insights into developing efficient systems for biofuel production (Wei and Huang, 2015). Normally, higher growth rate of microalgae is achieved by increasing the temperature to its optimum level (GonzálezFernández et al., 2012).

Studies on a large number of species have shown that both low and high temperatures can boost lipid productivity (Converti 


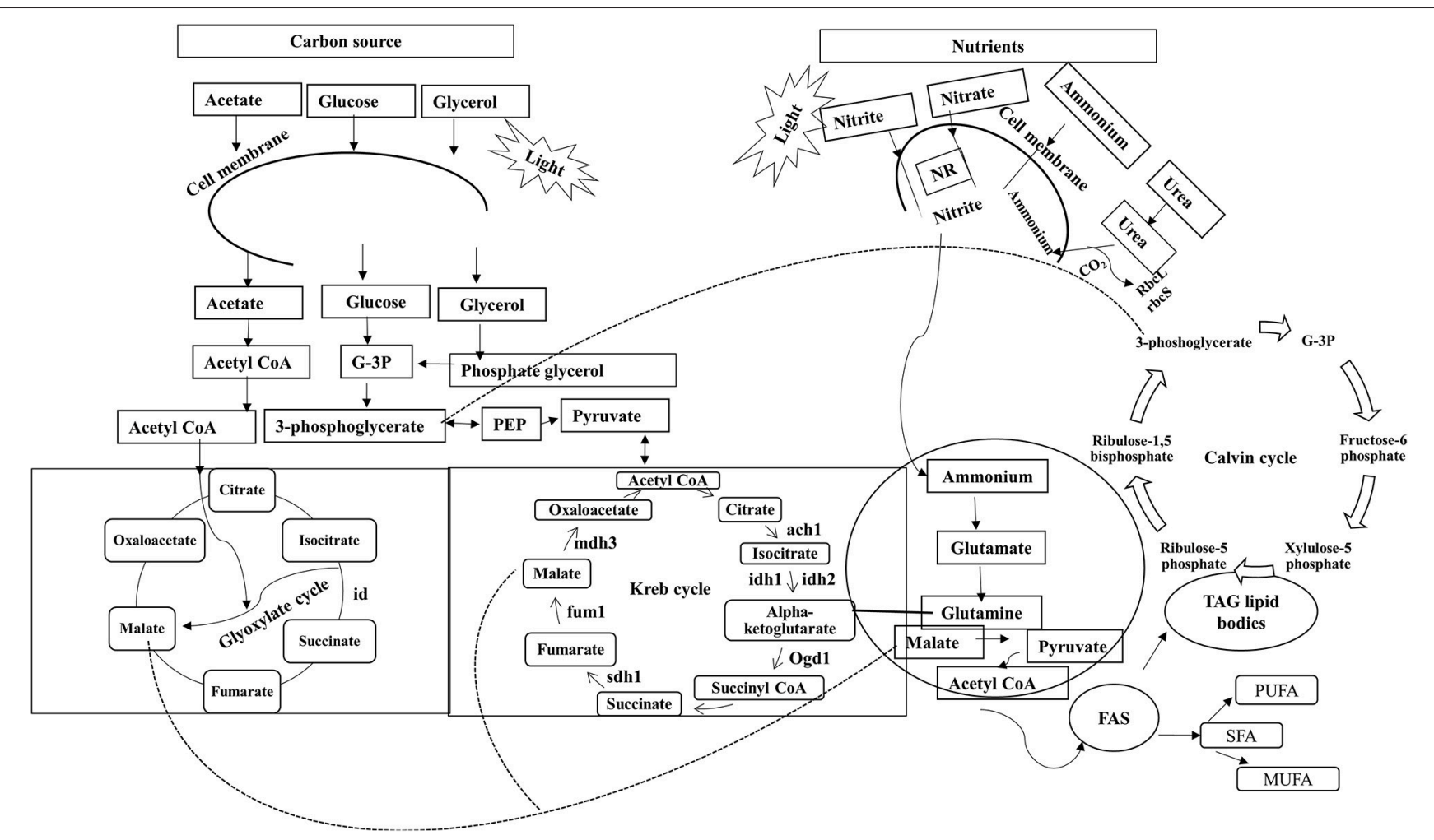

FIGURE 1 | Role of various carbon sources and nitrates in lipid biosynthesis. Sn-Glycerol-3 phosphate NAD+oxidoreducatse; ach 1, aconitate; idh 1, isocitrate dehydrogenase-NADH dependent; idh 2, isocitrate dehydrogenase-NADPH dependent; ogd 1, ketoglutarate dehydrogenase; fum1, fumarate hydratase; sdh 1, succinate dehydrogenase; mdh3, malate dehydrogenase; scla 1, succinate-CoA ligase (ADP forming); FAS, fatty acid synthesis; TAG, triacylglycerols; id, isocitrate dehydrogenase;rbcL, Ribulose bisophosphate carboxylase/oxygenase large subunit; rbcS, Ribulose bisophosphate carboxylase/oxygenase small subunit; prk, Phosphoribulokinase.

et al., 2009; Xin et al., 2011). Net lipid productivity decreased as temperatures increased from 25 to $35^{\circ} \mathrm{C}$ in Monoraphidium sp. SB2 (Wu et al., 2013); from 15 to $20^{\circ} \mathrm{C}$ in Nannochloropsis oculata (Converti et al., 2009); LX1, from 20 to $30^{\circ} \mathrm{C}$ in Scenedesmus sp. (Xin et al., 2011); and, from 14 to $30^{\circ} \mathrm{C}$ in Nannochloropsis sp. (Hu et al., 2006; Table 1). Both low and high temperatures are preferred for attaining higher lipid profiles, depending on the species: the levels of unsaturation in FAs increase under low temperatures, whereas those of total saturated FAs increase at high temperatures, as observed by Liu et al. (2005). The level of unsaturation is high at low temperatures mainly because of the higher concentration of dissolved oxygen (DO), which allows the oxygen-dependent enzymes, known as omega-3 desaturases, to function (Ward and Singh, 2005).

Besides lipids, ratio of saturated FAs to unsaturated FAs is species dependent but only partly because of innate differences in the ability of the species to synthesize lipids (either DHA or other FAs) under low temperatures. In species such as Nannochloropsis sp. and Phaeodactylum tricornutum, high (31.7 and $24.2 \%$, respectively) content of EPA C20:5 (omega-3) have been reported at low temperature stress (Jiang and Gao, 2004; Hu et al., 2006). Further, temperature is also known to affect carbohydrate production in microalgae; for example, in Spirulina sp. carbohydrate content increased up to $50 \%$ when temperature was increased from 25 to $40^{\circ} \mathrm{C}$ (Ogbonda et al., 2007). It seems that in many microalgal species temperature changes from low to high increases the lipids productivity. High temperature also favor biofuel properties. We have also noted that temperature stress is strain dependent and all strains do not thrive equally at high temperature. Therefore, temperature is a crucial stress factor to be taken in to account for optimizing lipids and biomass productivity.

\section{Light}

Light can bring significant changes in the chemical composition of microalgae. It is essential for photosynthesis, and together with photoperiod is a critical factor for microalgal growth (Wahidin et al., 2013). Light intensities of $100-200 \mu \mathrm{E} / \mathrm{m}^{2} / \mathrm{s}$ are commonly used for microalgal production (Zhao and $\mathrm{Su}, 2014$ ). For example, increasing the light intensity from 200 to 400 $\mu \mathrm{E} / \mathrm{m}^{2} / \mathrm{s}$ increased the rate of growth in microalgae (Radakovits et al., 2010). In Mychonastes homosphaera, Chlorella vulgaris, Raphidocelis subcapitata, and Scenedesmus sp. (Tang et al., 2011; Gonçalves et al., 2013; Liu et al., 2012), lipid productivity increased with increase in light intensity from low to high as shown in Table 1. Khotimchenko and Yakovleva (2005) reported high content of PUFA under low light intensity whereas high light 


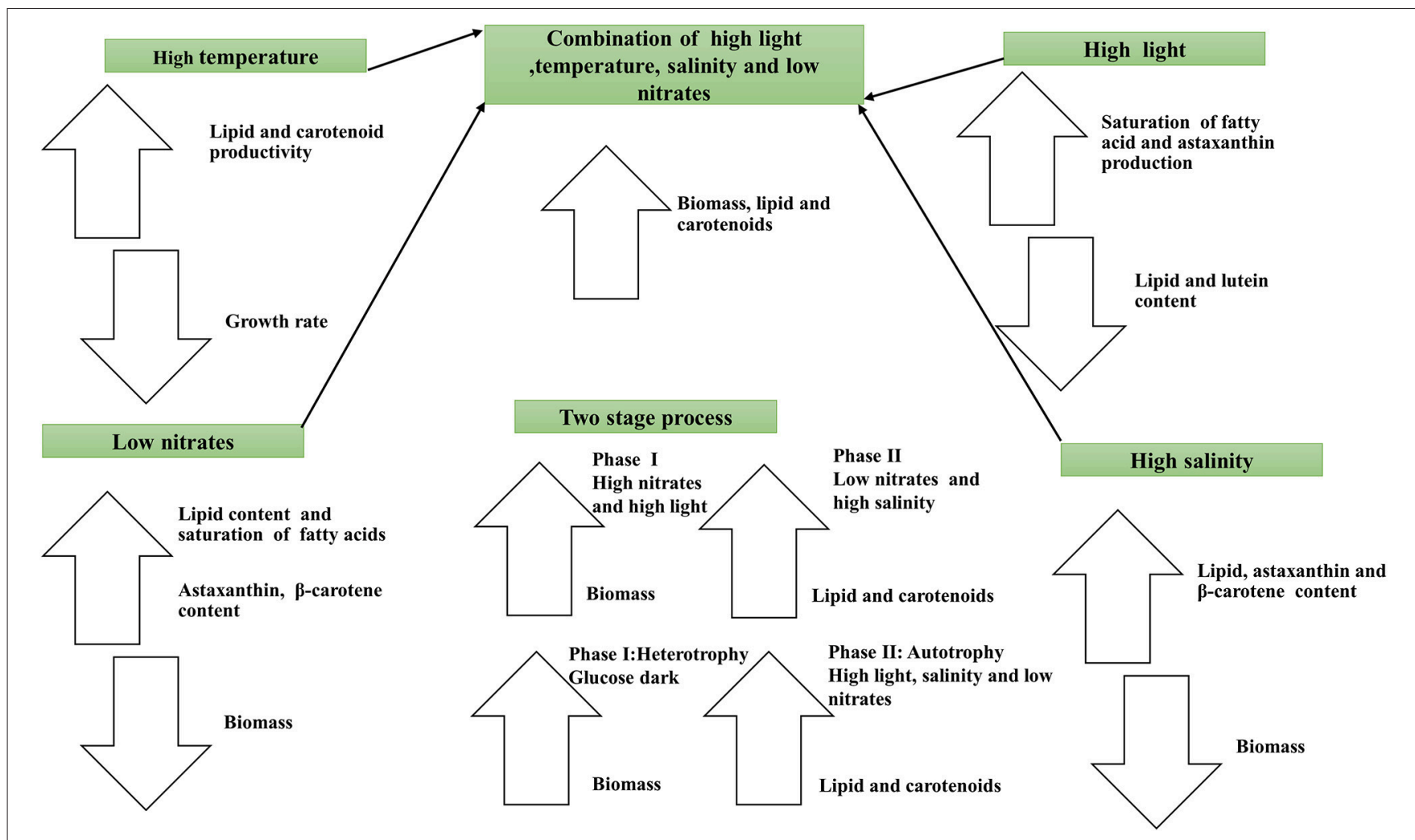

FIGURE 2 | Schematic diagram showing impact of environmental stresses on the lipid and carotenoids production.

intensity resulted in greater accumulation of saturated FAs and monounsaturated FAs.

Optimum light requirements varies with the microalgal species, and several parameters need to be considered in selecting the right combination when using artificial light in view of the overall energy balance considerations. It may be feasible to use high light intensities for enhanced production of lipids, biomass as well as suitable fatty acid profile for improving biofuel potential. Lipids productivity is therefore found to be influenced under high light stress. A serious concern is that the cells experience photoinhibition at high light. Thus, cultivation of microalgal strains in a two phase system, where in first phase cells are cultivated under low light and then shifted to high light in second phase can overcome the limitation caused by high light alone. This strategy may improve the overall biomass and lipid productivity and addresses appropriately the concern of photoinhibition.

\section{Nitrate}

Of all the macronutrients in the culture medium, nitrogen, which accounts for $1-10 \%$ of the total dry matter in microalgae (Wijffels et al., 2010), is quantitatively the most important nutrient affecting growth and lipid accumulation in various algae (Griffiths and Harrison, 2009). Nitrogen in different forms such as ammonium, nitrate, yeast, peptones, and urea, when used as a nutrient supplement, changes the rate of cell metabolism significantly (Chen and Chen, 2006) and plays a significant role in lipid synthesis (Figure 1). Increased lipid accumulation under nitrogen starvation conditions in several microalgae is well documented. For example, under nitrogen starvation, lipid production increased about twofold and onefold in Neochloris oleoabundans and Nannochloropsis sp. F\&M-M24 (Li et al., 2008; Rodolfi et al., 2009), respectively. Nitrogen deficiency also affects the biosynthetic pathway of carbohydrates (Cheng and $\mathrm{He}$, 2014). For example, carbohydrate content increased fourfold in Tetraselmis subcordiformis and by $29 \%$ in Scenedesmus obliquus CNW-N under nitrogen deficient conditions (Ji et al., 2011; Ho et al., 2012). Restricted supply of nitrogen and phosphorus shifts lipid synthesis from membrane lipids to neutral lipids (Juneja et al., 2013).

Moreover, lipid productivity increased with increasing nitrate concentration in Auxenochlorella pyrenoidosa (Singh et al., 2011) and Scenedesmus sp. (Xin et al., 2010), but the exact opposite pattern was observed in Auxenochlorella protothecoides (Shen et al., 2009) and C. vulgaris (Prîbyl et al., 2012), in which lipid productivity was higher at lower concentrations of nitrate (Table 1). A serious concern about cultivating microalgae under nitrogen limiting condition lowers biomass and consequently decrease the overall lipid productivity.

Two nitrogen limitation strategies has been defined to boost the lipids production in several microalgae. The first one is two stage nitrogen depletion as shown in C. vulgaris AG10032 (Mujtaba et al., 2012) in which microalgal cells are grown in nitrogen rich conditions to stimulate biomass growth and then 
TABLE 1 | Effect of stress factors on lipid and bioactive production.

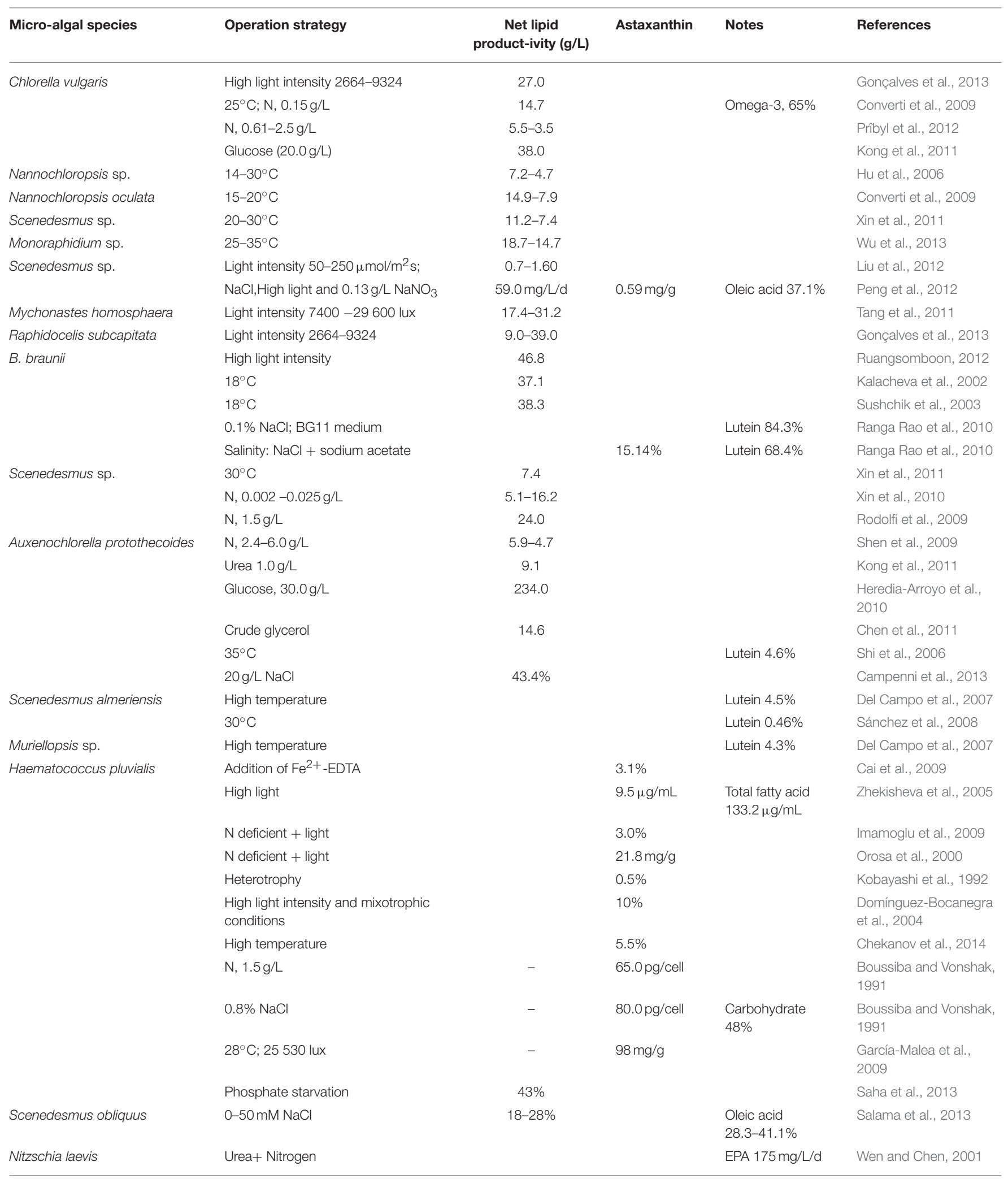


TABLE 1 | Continued

\begin{tabular}{|c|c|c|c|c|c|}
\hline Micro-algal species & Operation strategy & $\begin{array}{l}\text { Net lipid } \\
\text { product-ivity (g/L) }\end{array}$ & Astaxanthin & Notes & References \\
\hline \multirow[t]{6}{*}{ Nannochloropsis sp. } & $14^{\circ} \mathrm{C}$ & 7.2 & & $\begin{array}{l}\text { PUFA } 11.7 \% \\
\text { EPA } 7.9 \%\end{array}$ & Hu et al., 2006 \\
\hline & $22^{\circ} \mathrm{C}$ & & & EPA $25.3 \%$ & Hu et al., 2006 \\
\hline & $15^{\circ} \mathrm{C}$ & 14.9 & & & Converti et al., 2009 \\
\hline & $\mathrm{N}, 1.5 \mathrm{~g} / \mathrm{L}$ & 13.5 & & & Rodolfi et al., 2009 \\
\hline & $\mathrm{N}, 0.012 \mathrm{~g} / \mathrm{L}$ & 13.6 & & & Hu et al., 2006 \\
\hline & High $\mathrm{CO}_{2}$ & $9 \%$ & & & Hu and Gao, 2003 \\
\hline \multirow[t]{7}{*}{ Chromochloris zofingiensis } & $24-28^{\circ} \mathrm{C}$ & - & $12.3 \mathrm{mg} / \mathrm{L}$ & Lutein $21 \mathrm{mg} / \mathrm{L}$ & Del Campo et al., 2004 \\
\hline & $\mathrm{N}, 2.5 \mathrm{~g} / \mathrm{L}$ & - & $18.0 \mathrm{mg} / \mathrm{L}$ & Lutein $25 \mathrm{mg} / \mathrm{L}$ & Del Campo et al., 2004 \\
\hline & High light intensity & - & $19.0 \mathrm{mg} / \mathrm{L}$ & Lutein 24.7 mg/L & Del Campo et al., 2004 \\
\hline & Zero salinity + light & - & $15.0 \mathrm{mg} / \mathrm{L}$ & Lutein 15.0 mg/L & Del Campo et al., 2004 \\
\hline & Glucose, $50.0 \mathrm{~g} / \mathrm{L}$ & - & $10.0 \mathrm{mg} / \mathrm{L}$ & & Sun et al., 2008 \\
\hline & Glucose, $50.0 \mathrm{~g} / \mathrm{L}$ & - & $10.2 \mathrm{mg} / \mathrm{L}$ & & Feng et al., 2005 \\
\hline & $300 \mathrm{mM} \mathrm{NaCl}$ & & $0.8 \mathrm{mg} / \mathrm{L}$ & & Orosa et al., 2001 \\
\hline \multirow[t]{6}{*}{ Chlorella zofingiensis } & $\mathrm{N}$ deficiency & $65.1 \%$ & & & Feng et al., 2012 \\
\hline & $P$ deficiency & $47.7 \%$ & & & Feng et al., 2012 \\
\hline & High light intensity & & $1.5 \%$ & & Del Campo et al., 2004 \\
\hline & $0.2 \mathrm{M} \mathrm{NaCl}$ & & $4 \%$ & & Del Campo et al., 2004 \\
\hline & Mixotrophy & & $12.5 \mathrm{mg} / \mathrm{L}$ & & Ip et al., 2004 \\
\hline & Heterotrophy & & $32.0 \mathrm{mg} / \mathrm{L}$ & & Ip et al., 2004 \\
\hline \multirow[t]{3}{*}{ Dunaliella salina } & High light intensity & - & & $\beta$-carotene 3.1\% & Lamers et al., 2010 \\
\hline & $\mathrm{N}, 2.5 \mathrm{mM} 16 \% \mathrm{NaCl}$ & $37.7 \%$ & & & El-Baky et al., 2004 \\
\hline & N starvation & & & $\beta$-carotene $2.7 \%$ & Lamers et al., 2012 \\
\hline Dunaliella tertiolecta & $\mathrm{N}, 0.026 \mathrm{~g} / \mathrm{L} ; \mathrm{NH}_{4} \mathrm{Cl}(0.16 \mathrm{~m})$ & & & PUFA 73\% & Chen et al., 2011 \\
\hline C. vulgaris AG10032 & Two-stage nitrogen depletion & $77.1 \mathrm{mg} / \mathrm{L} / \mathrm{d}$ & & & Mujtaba et al., 2012 \\
\hline N. gaditana & $\begin{array}{l}\text { Two-stage (continuous culture }+ \\
\text { nitrate depletion) }\end{array}$ & $51.0 \mathrm{mg} / \mathrm{L} / \mathrm{d}$ & & & San Pedro et al., 2013 \\
\hline \multirow[t]{2}{*}{ Auxenochlorella pyrenoidosa } & $\begin{array}{l}\text { Semi-continuous (low-N medium } \\
\text { replacement) }\end{array}$ & $115.0 \mathrm{mg} / \mathrm{L} / \mathrm{d}$ & & & Han et al., 2013 \\
\hline & $\mathrm{N}, 0-0.4 \mathrm{~g} / \mathrm{L}$ & $1.4-6.66 \mathrm{~g} / \mathrm{L}$ & & & Singh et al., 2011 \\
\hline Chlamydomonas sp. JSC4 & Salinity: $\mathrm{NaCl}$ & $223.2 \mathrm{mg} / \mathrm{L} / \mathrm{d}$ & & & Ho et al., 2014b \\
\hline Arthrospira (Spirulina) platensis & Phosphate limitation & & & $\begin{array}{l}\text { Carbohydrate } \\
67 \%\end{array}$ & Markou et al., 2012 \\
\hline
\end{tabular}

transferred in to nitrogen starved medium for lipids production. The second one is one stage cultivation in which the medium contains desired nitrogen concentration and then as culture grows the nutrient starts depleting and finally starved conditions is achieved (Yen et al., 2013). The lipid and biomass accumulation in both of these strategies is species-dependent. Additionally, when nitrogen is deficient or lacking, many cyanobacteria produce hydrogen as a result of nitrogen fixation (Abed et al., 2009).

Thus, nitrate levels must be controlled throughout the growth in culture to maintain the nutrient contents of a medium stable and thereby prevent damage to the cell membrane, loss of biomass, and other changes in cell composition. Thus, screening based on lipid productivity, biomass production, and FAME profiles among strains grown under common parameters can achieve the highest resource utilization efficiency and maintain a positive material and energy balance under low cost nitrogen starvation technique. It is clear that under nitrogen limitation, the lipid production is increased in all microalgal species. However, biomass limitation under nitrogen deficient conditions is major concern, as lower biomass tends to reduce the net lipid productivity. Thus, cultivating microalgae in two phase system as described above can overcome the limitation of biomass production.

\section{Phosphate}

Phosphorous makes up considerably less than $1 \%$ of total algal biomass $(\sim 0.03-0.06 \%)$ and yet is an essential component in the medium for sustainable growth and development of microalgae (Hu, 2004; Hannon et al., 2010). Absence of phosphorus in a medium results in repression of photosynthesis (Belotti et al., 2014) and affects the growth of microalgae. However, phosphorus has a significant impact on the growth and metabolism of microalgae (Fan et al., 2014).

It has been observed that limitation of phosphates resulted in increased lipid accumulation in microalgal cells. For example, 
in the freshwater microalgae Scenedesmus sp. LX1 (Xin et al., 2010) and Botryococcus braunii (Venkatesan et al., 2013), net lipid productivity increased under phosphorus-limited (stress) conditions. Another study, by Markou et al. (2012), showed that under phosphorus-limitation, carbohydrate content increased from 11 to $67 \%$ in Arthrospira (Spirulina) platensis (Table 1). Thus, while designing the strategies to achieve higher lipid and biomass under environmental stresses combination of low nitrates and optimal phosphate concentration may increase the lipid and biomass production in one growth cycle. Developing such strategies in future can make the process more cost effective.

\section{Ammonium}

Ammonium is considered an energy-efficient source of nitrogen for microalgae because its uptake requires less energy (Li X. et al., 2010). In Cylindrotheca fusiformis and P. tricornutum, transport of ammonium may not be up-regulated by limiting nitrogen; however, when these species are transferred to a nitrate-rich medium, the ammonium transporters are expressed (Hildebrand, 2005). Ammonium as a substrate influences namely, PUFA content in Dunaliella tertiolecta (Table 1) but its influence on net lipid productivity is unknown and needs to be studied in a more diverse range of species. Although ammonium uptake by cells can lower the growth of microalgae, however is still a preferred nitrogen source in many cases as conditions can be controlled during microalgae cultivation to minimize any negative impact on growth.

\section{Salinity}

Salinity is an intricate stress factor affecting net lipid productivity in microalgal cells. Microalgal species can tolerate salinity stress up to an extent. Effects of salinity on marine algae have been examined by several researchers (Bartley et al., 2013; MartinezRoldan et al., 2014) however limited reports are available on freshwater microalgae. Dunaliella sp. is one such species that can tolerate high salinity stress and produce large quantities of lipid and biomass (Azachi et al., 2002). For example, in D. tertiolecta ATCC 30929 under high salinity concentration, increased lipid content up to $70 \%$ (Takagi et al., 2006). In the freshwater alga Scenedesmus sp., $\mathrm{NaCl}$ is believed to stimulate higher lipid production (Salama et al., 2013). However, excess salinity stress in cultivation medium inhibits photosynthesis which further reduces the biomass and net lipid productivity.

As discussed above, salinity stress tends to remarkably affects the fatty acid profile of microalgae. The changes in each fatty acid chain is species specific. Thus, cultivating microalgae in combination with salinity and nitrate stress in lab scale can further enhance the production of lipids and cell biomass in a single life cycle. A correlation between changes in the production of lipids and photosynthetic efficiency has not been well-studied across diverse microalgal strains.

Since $\mathrm{NaCl}$ is an inexpensive and readily available source of nutrients, adjusting the concentration of $\mathrm{NaCl}$ along with light intensities could further enhance the production of lipid, biomass, and biofuel properties in diverse microalgal species and hence can lower the cost of biofuel production. The effects of
$\mathrm{NaCl}$ in combination with those of other stress factors therefore needs to be examined further.

\section{Carbon}

Various concentrations and sources of carbon affect the overall composition of microalgal lipids. Both low and high concentrations of carbon dioxide have shown to induce the accumulation of saturated and unsaturated FAs, respectively ( $\mathrm{Hu}$ and Gao, 2003). Besides carbon dioxide, several microalgae use other carbon sources for production of lipids and other compounds under heterotrophic conditions, as described in the section on "Heterotrophic growth factors."

\section{Heterotrophic Growth Factors}

Heterotrophic organisms are those that lack the photosynthetic machinery and cannot generate energy through oxidation of inorganic compounds and therefore need an external carbon source. Carbon sources such as glucose, acetate, and glycerol are the most important element for the production of lipids and other compounds. The research on heterotrophic cultivation remained focused on Chlorella sp.

\section{Glucose}

Glucose is most preferred by diverse microalgal species as it can be easily assimilated and produces energy-rich compounds such as neutral lipids as storage products. Microalgae grown with glucose have shown higher growth rates than those grown on acetate and fructose as it produces more energy ( $\sim 2.8$ $\mathrm{kJ} / \mathrm{mol})$ in comparison to acetate $(0.8 \mathrm{~kJ} / \mathrm{mol})$ and stimulates the metabolic pathways involved in starch and lipid synthesis (Boyle and Morgan, 2009). Two major factors that affect the growth of heterotrophic microalgae are the innate ability of a strain and the conditions under which it is cultured. However, the overall consumption of carbon is ultimately determined by how efficiently it is metabolized and transported through the cell membrane (Azma et al., 2011). Many reports (HerediaArroyo et al., 2010; Kong et al., 2011, for example) show that a carbon source such as glucose at $30 \mathrm{~g} / \mathrm{L}$ and 20 $\mathrm{g} / \mathrm{L}$ increased the net lipid productivity in $A$. protothecoides and C.vulgaris (Table 1). Chlorella sp. grown heterotrophically produced $260 \%$ more lipids and $45 \%$ more total carbohydrates than that grown autotrophically (Miao and $\mathrm{Wu}, 2006$ ). Similarly C. protothecoides grown heterotrophically also showed fourfold higher lipid than that grown autotrophically (Xu et al., 2006). In almost all freshwater algae including Chlorella sp. (Leesing et al., 2011), N. oculata (Wan et al., 2011), and Chlorella sorokiniana (Wan et al., 2012), net lipid productivity increases with increase in glucose concentration as long as light is not a limiting factor. In C. sorokiniana, metabolic glucose flux occurs through glucose-6-phosphate dehydrogenase in which glucose6-phosphate isomerases act as a catalyst, and this species is known to generate more energy in the form of ATP than that generated by the autotrophic strain with light as energy source (Yang et al., 2000). It is evident that in Chlorella, the transport of ion across the cell membrane is proton dependent. Chlorella cells have an effective hexose $/ \mathrm{H}^{+}$transport system through which glucose from the medium is utilized (De Swaaf et al., 
2003). The metabolism of glucose is different and complex under autotrophic and heterotrophic conditions, and the pathways are also quite different.

Under heterotrophic conditions, glucose is utilized in the cell by means of the pentose phosphate pathway (Figure 1) whereas under autotrophic conditions, the Embden-Meyerhof pathway becomes functional (Yang et al., 2000). Efforts have been made to increase the lipid production by controlling metabolic growth during cultivation. Two stage cultivation process where in first heterotrophic cultivation (glucose) can obtain higher biomass and then shift to autotrophic mode (light) to achieve the desired products could influences net lipid productivity positively (Zhang et al., 2014). Although it is generally agreed that glucose is most preffered source of carbon. The effect of glucose on metabolism of microalgae varies significantly. Cultivation of microalgae in medium amended with glucose in presence of light can improve the biomass and lipids production in diverse microalgal species. In summary, information on concentration of glucose to be used for metabolic growth of algae is too diverse to reach some specific conclusions.

\section{Glycerol}

Glycerol is another carbon source that provides energy under heterotrophic conditions (Perez-Garcia et al., 2011). Glycerol boosts lipid productivity in freshwater microalgae but no data are available on its effect on the FA profile. Glycerol alone or in combination with glucose affects net lipid productivity: as shown in A. protothecoides (Heredia-Arroyo et al., 2010) and C. vulgaris (Kong et al., 2011). At higher concentration stress increases lipid productivity under mixotrophic conditions with low concentrations of glucose.

Organic carbon assimilation under mixotrophic conditions induced changes in both respiratory and photosynthetic metabolism in cyanobacteria (Vonshak et al., 2000); however, supplementing the organic carbon through glucose and that of energy in the form of light may convert the metabolic pathway in microalgal cells. Biochemical composition is thus influenced by light and by the concentration of nutrients in the medium (Kong et al., 2013). For example in P. tricornutum cultivated with $0.1 \mathrm{M}$ glycerol at $165 \mathrm{mmol}$ photons $/ \mathrm{m}^{2} / \mathrm{s}$ light intensity, growth increased up to $74 \%$ compared to autotrophic culture (Cerón et al., 2007). On the other hand, A. (Chlorella) protothecoides cultures with glycerol produced only half yield of total lipids that of cultures grown with glucose (Cerón-García et al., 2013). Grown on crude glycerol A. (Chlorella) protothecoides produced similar lipid and biomass to that grown in presence of glucose (Chen et al., 2011).

\section{Urea}

Urea is another carbon source that subsequently influences cell metabolic activity significantly. It affects the growth of microalgae, although very few studies have shown how it affects lipid productivity within the cell (Neilson and Larsson, 1980). Urease and urea amidoylases are the enzymes which help in metabolizing urea. However, it is unfortunate that Chlorella strains lack the enzyme urease (Kaplan et al., 1986), and the metabolism of urea is accompanied by ualse. However, some Chlorella sp. uses urea as a source of nitrogen (OhHama and Miyachi, 1992; Table 1). Thus, allowing the enzyme allophanate lyase in the ualse pathway helps in hydrolysing and converting urea to ammonium and bicarbonates (Morris, 1974).

Strategies using a combination of urea and nitrogen can promote the production of EPA in Nitzschia laevis (Wen and Chen, 2001). The more indepth research efforts are needed to understand role of urea and its impact on multidirectional metabolic pathways. Cultivation of microalgae under high urea concentration can increase the biomass production in different microalgae. All microalgae strains cannot assimilate urea therefore selection of strain and their cultivating conditions needs major attention.

\section{MICROALGAL SYNTHESIS OF CAROTENOIDS}

Microalgae are known to produce pigments and bioactive compounds, of which three are particularly promising: chlorophyll, phycobilins, and carotenoids (Abalde et al., 1991). Chlorophyll is mainly found in algae, cyanobacteria and higher plants. Carotenoids are divided in to primary and secondary carotenoids. Lutein is considered a major carotenoid since it acts as a primary carotenoid maintaining the membrane integrity of cells and protecting cells from many forms of stress (Sánchez et al., 2008), whereas astaxanthin is considered a secondary carotenoid, present in lipid bodies outside the chloroplast (Grünewald et al., 2001), and has potential applications in human health. Astaxanthin and canthaxanthin are considered major ketocarotenoids in algae, fungi, and bacteria (Abe et al., 2007) and therefore of great interest for biotechnological applications and as feed supplements in aquaculture (Yaakob et al., 2014).

In plants and algae, carotenoids are synthesized in the chloroplasts around the nucleus and their accumulation is effected only when they are exposed to some stress factors (Lemoine and Schoefs, 2010). Astaxanthin accumulation in lipid bodies outside the chloroplast increases under several stress conditions (Wang and Peng, 2008). Phycobiliproteins are water soluble pigments found in cyanobacteria and eukaryotic algae (MacColl, 1998). The above pigments are high-value compounds, produced from Porphyridium cruentum, Synechococcus sp., and Chlorella sp. (Rodrigues et al., 2014). Due to their color, carotenoids are used in dyes and as coloring agents (Yuan et al., 2011; Christaki et al., 2013).

Astaxanthin, $\beta$-carotene, and lutein are the main promising microalgal pigments with high market potential (Table 2). The above pigments are vital for the survival of a cell because they form the basic and functional components of photosynthesis in the thylakoid membrane (Guedes et al., 2011). Other pigments such as xanthophylls, mostly found in cyanobacteria, are well linked with chlorophyll-binding polypeptides (Grossman et al., 1995); however, in a few green microalgae, xanthophylls 
TABLE 2 | Market potential of products.

\begin{tabular}{|c|c|c|c|c|c|}
\hline $\begin{array}{l}\text { Bioactive } \\
\text { compound }\end{array}$ & Mode of production & $\begin{array}{l}\text { Cultivation } \\
\text { method }\end{array}$ & Applications & Key players & $\begin{array}{l}\text { Market (USD, } \\
\text { million) }\end{array}$ \\
\hline \multirow[t]{4}{*}{$\begin{array}{l}\text { Nutraceutical } \\
\text { astaxanthin }\end{array}$} & $\begin{array}{l}\text { Haematococcus pluvialis, } \\
\text { freshwater green alga } \\
\text { (Chlorophyceae) }\end{array}$ & $\begin{array}{l}\text { Tubular } \\
\text { phorobioreactor } \\
\text { (Two phase) }\end{array}$ & $\begin{array}{l}\text { Natural anti-oxidant; prevents age- related macular } \\
\text { degeneration, neuro-degenerative diseases, } \\
\text { dyspepsia, sunburn, hypertension, benign } \\
\text { prostrate hyperplasia; improves sperm fertility, } \\
\text { muscle function, normalizes cardiac rhythm; helps } \\
\text { in stress management and stroke repairs }\end{array}$ & AlgaTech, Israel (a) & 200 \\
\hline & & & & $\begin{array}{l}\text { Blue Biotech, } \\
\text { Germany (b) }\end{array}$ & \\
\hline & & & & $\begin{array}{l}\text { Fuji Chemicals, } \\
\text { Japan (c) }\end{array}$ & \\
\hline & & & & BioReal, Sweden (d) & \\
\hline \multirow{3}{*}{$\begin{array}{l}\text { Biorefinery } \\
\text { carotenoids } \\
\text { (astaxanthin, } \\
\text { lutein), PUFA, } \\
\text { lipids and proteins }\end{array}$} & $\begin{array}{l}\text { Chromochloris } \\
\text { zofingiensis, freshwater } \\
\text { green alga } \\
\text { (Trebouxiophyceae) }\end{array}$ & $\begin{array}{l}\text { Tubular } \\
\text { photobioreac- } \\
\text { tor one } \\
\text { stage }\end{array}$ & $\begin{array}{l}\text { Defends cells from damaging effects from free } \\
\text { radicals and age-related macular degeneration and } \\
\text { cataract }\end{array}$ & $\begin{array}{l}\text { Blue Biotech, } \\
\text { Germany (b) }\end{array}$ & 40 \\
\hline & & & & $\begin{array}{l}\text { Earthrise, USA and } \\
\text { Dainippon, Japan (e) }\end{array}$ & \\
\hline & & & & $\begin{array}{l}\text { Chlorella Co., } \\
\text { Taiwan (f) }\end{array}$ & \\
\hline \multirow[t]{2}{*}{ EPA } & $\begin{array}{l}\text { Phaeodactylum } \\
\text { tricornutum, hetrokont, } \\
\text { diatoms }\end{array}$ & Hybrid raceway & $\begin{array}{l}\text { Produced for cosmetics and aquaculture; } \\
\text { anti-inflammation (peptide) used as feed additives }\end{array}$ & Soliance (g) & 300 \\
\hline & $\begin{array}{l}\text { Nannochloropsis spp. } \\
\text { Heterokonts } \\
\text { (Eustigmatophyceae) }\end{array}$ & $\begin{array}{l}\text { Hybrid two- } \\
\text { stage }\end{array}$ & & $\begin{array}{l}\text { Blue Biotech, } \\
\text { Germany (b) }\end{array}$ & \\
\hline $\mathrm{DHA}$ & $\begin{array}{l}\text { Schizochrytium, } \\
\text { Cryptocodinium }\end{array}$ & & $\begin{array}{l}\text { Food supplement (omega-3 fatty acid, brain } \\
\text { development for children) }\end{array}$ & $\begin{array}{l}\text { Xiamen Huison } \\
\text { Biotech Co. (China), } \\
\text { Martek (USA) }\end{array}$ & 1.5 billion \\
\hline Fucoxanthin & $\begin{array}{l}\text { Laminalia japonica } \\
\text { (Laminariaceae) }\end{array}$ & & $\begin{array}{l}\text { Prevents liver and skin cancer owing to its } \\
\text { ant-ioxidant activity, and breast and prostate } \\
\text { cancer through induction of apoptosis }\end{array}$ & $\begin{array}{l}\text { AlgaNova } \\
\text { International, China }\end{array}$ & $\begin{array}{l}\text { Yet to reach } \\
100\end{array}$ \\
\hline Phycocyanin & $\begin{array}{l}\text { Spirulina platensis } \\
\text { (Phormidiaceae) }\end{array}$ & $\begin{array}{l}\text { Open ponds, } \\
\text { Natural lakes }\end{array}$ & $\begin{array}{l}\text { Used in immunofluorescent labeling; as natural } \\
\text { colors in food and cosmetics, anti-oxidant, } \\
\text { anti-tumor, anti-cancer agents; prevents } \\
\text { atherosclerosis; exerts inhibitory effects, induces } \\
\text { allergic inflammatory response, and helps in stem } \\
\text { cell regeneration especially in bone marrow and } \\
\text { blood cells }\end{array}$ & $\begin{array}{l}\text { Parry nutraceuticals, } \\
\text { SandaKing (Japan) } \\
\text { (Photonz. Corporate) }\end{array}$ & 50 \\
\hline$\beta$-carotene & Dunaliella Salina & Open raceway & $\begin{array}{l}\text { Natural colorant; prevents skin, ovarian and breast } \\
\text { cancers, solar keratosis, arthritis, bronchitis }\end{array}$ & $\begin{array}{l}\text { Nutrition \& Health, } \\
\text { Australia; Cyanotech, } \\
\text { Hawaii, USA (h) }\end{array}$ & 261 \\
\hline
\end{tabular}

(a)www.algatech.com (2013).

(b)www.bluebiotech.de/(2013).

(c)www.fujichemical.co.jp (2013).

(d)www. bioreal.se (2013).

(e)www.earthrise.com (2013).

(f)Chacon-Lee and Gonzalez-Marino (2010).

(g)www.soliance.com/ (2013).

(h)http://www.reportlinker.com/p096628-summary/The-Global-Market-for-Carotenoids.html Last accessed 29/6/2013.

are localized, and synthesized within the plastid, whereas in Haematococcus sp., astaxanthin accumulates in the cytoplasm (Eonseon et al., 2003). Carotenogenesis pathways and relative enzymes have been studied in cyanobacteria (Takaichi and Mochimaru, 2007). The enzymes and genes involved in carotenoid synthesis are different in algae and cyanobacteria (Takaichi, 2011). Haematococcus pluvialis, D. salina, and
Chlorella sp. are well-studied candidates for the production of commercially important carotenoids (Gimpel et al., 2015) (Table 2). Furthermore, in photosynthetic organisms these carotenoids play important roles in either absorbing energy or protecting cells from photo-oxidative damage (Demming-Adams and Adams, 2002). Although, the pigments are basically associated with exposure and duration of light 
intensity. The production of metabolites under dark conditions is yet to explored.

\section{STRATEGIES TO ENHANCE MICROALGAL CAROTENOIDS PRODUCTION}

Secondary carotenoids synthesis is altered by changes in culture conditions and their production can be enhanced by controlling several stress factors (Lemoine and Schoefs, 2010) as shown in schematic Figure 2. Carotenogenesis is enhanced by reactive oxygen species (ROS), under stress conditions such as high light intensity, salt stress (Kobayashi et al., 1993). Because of this, astaxanthin is believed to protect the body from such freeradical-linked diseases as oral, colon, and liver cancers (Guerin et al., 2003).

Several unfavorable environmental conditions such as nutrient deficiency, intense irradiation, and excessive photosynthesis lower the rate of electron transfer and, in turn, photo-oxidative damage (Solovchenko et al., 2011). Primary carotenoids, such as lutein degrade under stress and therefore their biomass content is decreased. However, several primary carotenoids, such as $\beta$-carotene act as secondary metabolite and therefore accumulate under stress conditions (Rabbani et al., 1998). Carotenoids content and accumulation in high concentration in total biomass varies under several stress factors. Combined effect of several stress factors have enhanced the production of astaxanthin in H. pluvialis (Ben-Amotz, 2004).

Two stage cultivation process (Aflalo et al., 2007), continuous process (Zhang et al., 2009) have been opted by researchers for increasing the astaxanthin production in microalgae. Under stress conditions, $\beta$-carotene is accumulated in lipid bodies with in the chloroplast with highest content of $12 \%$ dry cell weight (Del Campo et al., 2007). Similar to astaxanthin, $\beta$-carotene content in microalgal species increases when growth is arrested under several stress factors (Lamers et al., 2012). Lutein production in Muriellopsis sp. and Scenedesmus almeriensis is unaffected under stress conditions (Table 1) unlike astaxanthin and $\beta$-carotene (Del Campo et al., 2000). However, these two species have been tested in large scale cultivation system for commercial purpose (Fernández-Sevilla et al., 2010). Autotrophic and mixotrophic cultivation has been studied in detailed below to develop the method for enhanced production of metabolites.

\section{Autotrophic Growth Factors Temperature}

Temperature plays an important role in the accumulation of carotenoids within microalgal cells. Higher temperatures result in increased accumulation of carotenoids in microalgal species due to increased photo-oxidative stress (Tripathi et al., 2002). Temperature affects the synthesis of astaxanthin in $H$. pluvialis (Chekanov et al., 2014) and Chromochloris zofingiensis (Del Campo et al., 2004) as depicted in Table 1. High temperature is rarely used for inducing astaxanthin production because it is reported to reduce biomass yield drastically, thereby leading to an overall reduction in astaxanthin production.
Temperatures above $28^{\circ} \mathrm{C}$ were found to decrease the overall productivity of astaxanthin in C. zofingiensis (Del Campo et al., 2004) because ROS are assimilated in greater quantities during photosynthesis, which causes the accumulation of astaxanthin (Kovacic, 1986). In Dunaliella salina, high temperature results in accumulation of lutein (García-González et al., 2005). In addition, in $S$. almeriensis the lutein content and net biomass increased to $0.46 \%$ and $0.53 \mathrm{~g} / \mathrm{L}$, respectively, when temperatures reached up to $30^{\circ} \mathrm{C}$ (Sánchez et al., 2008). A similar trend was also observed in C. protothecoides (Shi et al., 2006) (Table 1). In contrast low temperature increased $\beta$-carotene and $\alpha$-carotene content in Dunaliella sp. (Gómez and González, 2005). However, overall lutein content was affected when temperature was increased from 20 to $33^{\circ} \mathrm{C}$ in Muriellopsis and S. almeriensis (Del Campo et al., 2007) in one growth cycle (Table 1).

Temperature is the only factor which enhanced the production of lutein. Temperature effect on carotenoids production is not well-known, however it is observed high temperature tends to accumulate more lutein content where as it has no effect on astaxanthin and $\beta$-carotene production. Autotrophic cultivation of microalgae under temperature stress is species dependent. For enhanced production of carotenoids, cultivating microalgal strains at high temperature in combination with other stress factors such as light and salinity could be more effective.

\section{Light}

Light availability is one of the most serious limiting factors for production of several carotenoids, biomass (Cordero et al., 2011), and FAs (Ward and Singh, 2005). Little is known about carotenoids metabolism as affected by the quality of light (Fu et al., 2013). Light intensity as well as photoperiod affect growth, biomass, and other metabolites of interest in diverse microalgae species (Seyfabadi et al., 2011; Khoeyi et al., 2012). Increasing the light intensity resulted in a threefold increase in astaxanthin in (Table 1) H. pluvialis (Del Campo et al., 2004). Besides astaxanthin, $\beta$-carotene content was also increased in $D$. salina up to $3.1 \%$ of dry cell weight (Table 1) when light intensity was changed from 100 to $1000 \mu \mathrm{mol}$ photons $/ \mathrm{m}^{2} / \mathrm{s}$ (Lamers et al., 2010). Lutein content is also affected under high light intensity; for example, in Muriellopsis sp. lutein content peaked at $460 \mu \mathrm{mol}$ photons $/ \mathrm{m}^{2} / \mathrm{s}$. High light intensity alone helps in promoting the growth of microalgae but reduced overall lutein content in Scenedesmus sp. (Xie et al., 2013). In all the above species, greater exposure to light increases the concentration of astaxanthin and lutein.

The production of lutein was studied in C. sorokiniana (Cordero et al., 2011) and Scenedesmus sp. (Sánchez et al., 2008) because both the species have a high growth rate and high lutein-accumulating power. On the other hand, formation of primary $\beta$-carotene and SC is affected by low as well as by high light intensity: although photosynthesis occurs under both levels, under low light intensity it generates fewer oxygen radicals, whereas under high light intensity, cells are unable to utilize all the energy that is generated, and the surplus energy activates more oxygen molecules, leading to the formation of SC such as astaxanthin (El-Baz et al., 2002). 
Such an exception has not been reported in $H$. pluvialis, in which cells continue to generate oxygen molecules during photosynthesis. In summary, carotenogenesis in photosynthetic cells is correlated with different developmental changes and depends upon environmental conditions. It is observed that, high light favors the production of astaxanthin and $\beta$-carotene. Cultivation of microalgae under high light stress in combination with nitrates can further enhance the production of biomass and carotenoids (like astaxanthin, lutein and $\beta$-carotene).

\section{Nitrate}

Nitrate as a stress factor influences not only lipid production but also affects carotenoids accumulation in green algae. Several factors trigger carotenoids synthesis and should be considered in developing microalgal products. Limiting nitrogen in the growth medium increases the production of SC but lowers overall biomass yield (Cordero et al., 2011). Ammonium nitrate have less impact on microalgal growth and carotenogeneis (Markou and Nerantzis, 2013). Moreover, total astaxanthin content of $3 \%$ dry cell weight (Table 1) was obtained in a nitrogendeficient medium (Imamoglu et al., 2009). Absence or low levels of nutrients including nitrogen stimulate rapid physiological responses, which further trigger the secondary biosynthetic pathways (Touchette and Burkholder, 2000).

Lutein accumulation in microalgae cells is highly dependent upon nitrogen concentration within the medium (Del Campo et al., 2000). Under nitrogen-limiting conditions, carotenoids ( $\beta$ carotene, astaxanthin, and canthaxanthin) begin to accumulate in aerial microalgae (e.g., Coelastrella sp. and many more), and the color of cells changes from green to red (Abe et al., 2007). Chromochloris zofingiensis, however, is an exception, and accumulates lutein and astaxanthin as the main compounds (Table 1). Besides lutein and astaxanthin, $\beta$-carotene content increased up to $2.7 \%$ of dry cell weight in D. salina (Lamers et al., 2012) under nitrogen-depleted conditions (Table 1). In general, nitrogen deficiency has a greater impact than excess nitrogen on carotenoids production, mainly that of astaxanthin in $H$. pluvialis (Table 1), because a culture growing in a nitrogen-rich medium requires carbon to assimilate the nitrogen. Low nitrogen, on the other hand, leads to greater competition for carbon, which is required for the synthesis of both carotenoids and proteins (Borowitzka et al., 1991).

Hence a combination of urea and other nitrogen sources achieved maximal lutein production in $A$. protothecoides under heterotrophic conditions (Shi et al., 2000). A two phase system where both nitrogen enriched and deficient medium is used in presence of high light intensity stimulate the growth of microalgae during first phase with biomass enhancement and in second phase deficient medium enhances carotenoids enrichment. These observations could be vital considerations toward defining future cultivation strategies.

\section{Salinity}

Salinity has diverse effects on species and varies greatly across habitats (Table 1). The effect of salinity on growth and carotenoids formation is complex. Several species of microalgae can tolerate a range of salinity levels because of efficient osmoregulation, which involves continuous synthesis of glycerol (Pick, 2002). For example, carotenoids production differs among the four species of Dunaliella, namely D. salina, D. bardawil (Gomez et al., 2003), D. tertiolecta, and D. viridis (Hadi et al., 2008): D. tertiolecta produces greater quantities of carotenoids at optimum salinity levels whereas $D$. viridis does so only at higher salinity levels. However, salinity affects overall $\beta$-carotene content (Coesel et al., 2008). Salt stress of 5.5 M increased carbohydrate content in D. salina (a 2.5-fold increase) (Mishra et al., 2008). Increase in salinity increases nitrogen and carbon content, which forces the cell to produce glycerol and amino acids to cope with the high salinity (Jiménez and Niell, 1991).

In Chromochloris zofingiensis, lutein and astaxanthin accumulate only during later stages of growth because both are synthesized from a common precursor, lycopene, with primary carotenoids as derivatives (Hirschberg et al., 1997). The astaxanthin content increased under salinity stress in H.pluvialis and C. zofingiensis (Table 1). However, H. pluvialis cannot tolerate salt concentrations above 10\% w/v (Borowitzka et al., 1991), whereas concentrations higher than $2 \mathrm{mM}$ of $\mathrm{NaCl}$ decreased total lutein content (Cordero et al., 2011) in $C$. sorokiniana. Salinity stress can further stimulate the production of total carotenoids. However, anything in excess causes harm to the metabolic system of microorganism. Thus, we inferred that $\mathrm{NaCl}$ stress have positive impact on increasing the astaxanthin and $\beta$-carotene production however it has no impact on the lutein production. Cultivating microalgal strains in the medium containing high nitrates and high salinity together can increase the production of lutein, astaxanthin and $\beta$-carotene, while using a two stage cultivation process. Combination of several environmental stresses in one culture medium could become a novel strategy for enhancing the metabolites production during single growth cycle. However, the metabolic pathway functioning of different stress factors in diverse microalgal strains is a complex phenomenon and has not been well-explored and analyzed.

\section{Iron}

Iron is needed for the growth of microalga such as Dunaliella. Of all the micronutrients, iron was the best for accumulation of astaxanthin in cysts of $H$. pluvialis (Kobayashi et al., 1993) because iron acts as a chelating agent; can scavenge hydroxyl radicals in the Fenton reaction widely used in the enzyme system of animals, microbes, and plants (Raven et al., 1999); and acts as limiting factor under hypersaline conditions. The site for assimilation of iron is usually the plasma membrane (Polle and Song, 2009). He et al. (2007) reported that phosphorus, iron, and sulfur are important nutrients for enhancing astaxanthin accumulation. However, supplementing the medium with $\mathrm{Fe}^{2+}$ EDTA (Table 1) produced biomass that contained 3.1\% dry cell weight astaxanthin in H.pluvialis (Cai et al., 2009).

\section{Heterotrophic and Mixotrophic Growth Modes}

Published work on the effect of glucose on astaxanthin production is scant because microalgae cannot use external carbon sources efficiently. However, the ability to use external 
carbon varies with the species and culture conditions. Under heterotrophic conditions, glucose is used as a carbon source for up-regulation of some genes, namely $b k t$, chy-b, and $p d s$, in H. pluvialis, Chromochloris zofingiensis (Sun et al., 2008), and Synechocystis sp. (Ryu et al., 2004). Glucose is reported to be the end product of photosynthesis, and any organism growing under light may be able to use glucose effectively (GarcíaGonzález et al., 2005). In C. zofingiensis (Sun et al., 2008) and A. protothecoides (Shi et al., 1997), the yield of astaxanthin increases with increase in glucose concentration. Whereas increase in glucose concentration further increases lutein content in Chlorella (Shi et al., 2000). Under heterotrophic conditions, $H$. pluvialis grows very slowly; however, it accumulates a total of $0.5 \%$ (dry cell weight) of astaxanthin (Kobayashi et al., 1992) as depicted in Table 1. Under mixotrophic conditions, both growth and astaxanthin production are increased (Wang et al., 2004). However, another study reported astaxanthin yield of $12.5 \mathrm{mg} / \mathrm{L}$ in C. zofingiensis under mixotrophic conditions (Ip et al., 2004), and in glucose-supplemented medium the yield increased to $32 \mathrm{mg} / \mathrm{L}$ (Table 1). Hence, different nutrients such as nitrogen and carbon affect growth and other parameters such as growth rate and pigment content, thereby affecting the biochemical composition of microalgae (Orosa et al., 2000). In summary, mixotrophic cultivation are more preffered for enhancing the biomass, lipid and carotenoids yield in microalgal species.

\section{HIGH-VALUE PRODUCTS FROM MICROALGAE}

Algae can produce a variety of antioxidants and pigments (carotenoids including fucoxanthin, lutein, $\beta$-carotene, astaxanthin, and phycobilliproteins); LC-PUFA; and proteins (the essential amino acids methionine, threonine, and tryptophan) (Gouveia, 2014) with wide applications in food, feed, agriculture, and pharmaceutical industries (Markou and Nerantzis, 2013) (Figure 3). Microalgae are useful in aquaculture as sources of biomolecules and biomass that can improve the nutritional value of food or provide additional health benefits (Yaakob et al., 2014). However, for food and aquaculture applications in particular, low cost production is important for commercial success. The production yields of microalgal biomass is higher under heterotrophic conditions than under photoautotrophic conditions. Although, the relative cost of substrate to products with respect to energy balances is more cost intensive in heterotrophic cultivation (Chen et al., 2011) compared to photoautotrophic.

The present study shows that microalgae are too expensive as a source for biofuel, without the co-production of more valuable compounds. Table 2 gives recent estimates of the production cost of microalgal value-added products along with omega FAs. Currently, three major production systems are used for microalgal cultivation: open raceway ponds, horizontal tubular photobioreactors (PBRs), and flat-panel PBRs. Raceway ponds are much better than open ponds for cultivation of microalgae (Jacob-Lopes et al., 2014). Several semi-commercial or commercial projects using open ponds and PBRs for producing value-added products from microalgae are operational worldwide (Table 2). The omega-3 FA market was worth $\$ 690$ million in 2004, and the Asian Omega-3 PUFA market was expected to be worth $\$ 596.6$ million in 2012 (Seambiotic, 2013). The global market for EPA and DHA is estimated at $\$ 300$ million and $\$ 1.5$ billion, respectively, (Table 2). A few industries in Europe and USA have also started producing EPA and DHA from microalgae (Table 2), to be used as food additives. In near future, the market for PUFA particularly omega-3) is expected to grow. PUFA [particularly, $\gamma$-linolenic acid (GLA, 18:3 $\omega-6)$, (EPA, 20:5 $\omega-3$ ), arachidonic acid (ARA, 20:6 $\omega$ $6)$, docosapentaenoic acid (22:5 $\omega-3)$, and (DHA, 22:6 $\omega$ $3)$ ] is gaining interest because of their application in health industry (Fraeye et al., 2012). Table 2 provides an overview of the main products from microalgae that are in the early stage of development (particularly lutein), notably for the cosmetics industry. Cyanobacteria strains produce various intracellular and extracellular metabolites that show antibacterial, antifungal, antiviral, antitumor, anti-HIV, anti-inflammatory, antioxidant, antimalarial, or herbicidal properties (Semary, 2012).

One of the major producers of Spirulina, Hainan Simai Pharmacy Co. (China), produces 3000 tonnes of biomass annually (Priyadarshani and Rath, 2012). Table 2 shows that a large group of industries produce $\beta$-carotene, a food additive, from $D$. salina in Australia. Many species produce high concentrations of $\beta$-carotene, astaxanthin, and canthaxanthin, which have significant applications as antioxidants and natural dyes (Table 2). The market cost of $\beta$-carotene estimated at $\$ 261$ million by 2010 as shown in Table 2 and expected to grow up to $\$ 334$ in 2018. On the other hand, the total market value of cyanobacteria and phycobiliproteins is estimated at \$6-\$11 million (Yaakob et al., 2014). The commercial market for lutein is $\$ 150$ million a year in USA (Fernández-Sevilla et al., 2010) and was $\$ 233$ million in 2010 in the poultry industry and as a nutritional supplement (Borowitzka, 2013) which is expected to grow up to $\$ 309$ by 2018 . The pigment phycocyanin is produced from Spirulina platensis by a small number of industries and even lutein and astaxanthin are produced by many industries worldwide (Table 2). Recent trends show that industries are entering the markets for EPA, DHA, astaxanthin, and phycocyanin. Products that are well-studied include fucoxanthin, proteins, $\beta$-glucan (a polysaccharide) and phycoerithrin (a pigment).

\section{COMBINED PRODUCTION OF LIPIDS AND CAROTENOIDS}

Besides lipids having biofuel properties, various high- value added products such as vitamins, polysaccharides, phycobilins, antioxidant can also be extracted from same biomass which could be used as commodities in several biotechnology industries (Mata et al., 2010). For example, polysaccharides which are produced by several microalgal species has potential use in health industry (Markou and Nerantzis, 2013). The combined production of lipids and carotenoids from the same microalgal biomass therefore seems promising (Table 1). Members of 

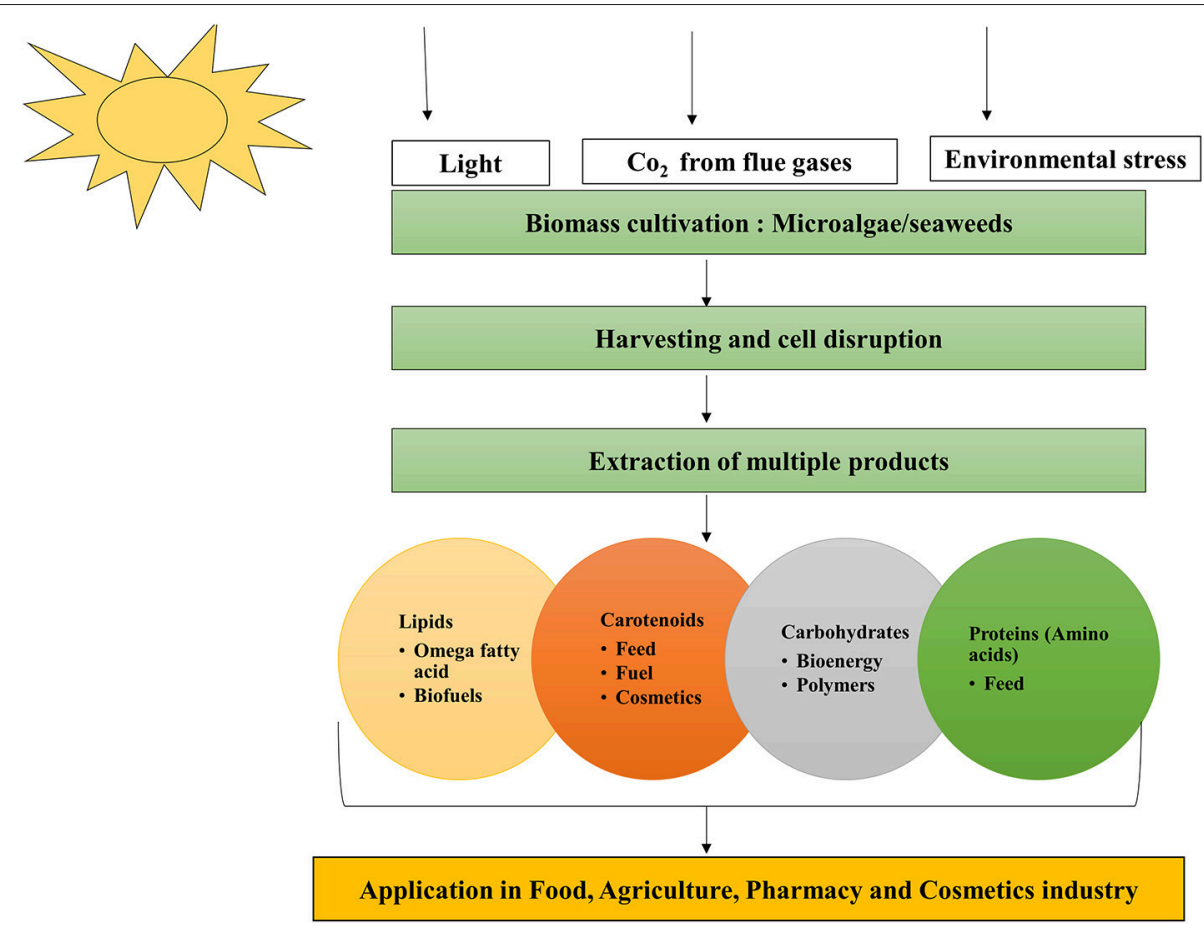

FIGURE 3 | Microalgae the biorefinery concept.

Chlorella sp. Well-known for lipids production, being now used in cosmetic industry for their protein extracts (Stolz and Obermayer, 2005). Furthermore, C. vulgaris extract is used in antiaging creams and tissue regeneration (Spolaore et al., 2006). Data from the literature shows as depicted in Table 1 that lipid synthesis is dependent upon carotenoids accumulation (Zhekisheva et al., 2005) when exposed to high light. Fatty acid production is linked to carotenoids accumulation (Zhekisheva et al., 2002; Cerón et al., 2007). In H. pluvialis, carotenoids production is dependent upon TAGs production. However, astaxanthin accumulation within these TAGs bodies involves the transfer of intermediates from the early $s$ teps of the biosynthetic pathway in chloroplasts (Grünewald et al., 2001). Under high light intensity, Haematococcus sp. accumulates astaxanthin within its cells (Boussiba and Vonshak, 1991), overproducing primary carotenoids ( $\beta$-carotene). In addition to astaxanthin accumulation, Haematococcus pluvialis (Zhekisheva et al., 2005) and Scenedesmus sp. (Peng et al., 2012) have the potential to produce multiple biomolecules at the same time (Table 1). However, a combination of several stress factors may results in the enhanced production of carotenoids and lipids from the same biomass. For instance, in D.salina combined the use of light stress apparently increased the production of $\beta$-carotene (Table 1; Lamers et al., 2010). Another study conducted by Peng et al. (2012) showed accumulation of lipids and carotenoids under salinity and light stress. The emerging value of a few carotenoids (especially lutein) in the prevention and treatment of disorders, such as degenerative diseases, and of omega FAs (EPA and DHA) as a general wellness product, has strengthened the biorefinery model.

Despite the promising cultivation conditions for production of multiple metabolites from microalgae, the process has not been yet commercialized due to lack of reactors and methods that can produce large amount to supply to market. In some cases, because of limited production of biomass under stress, the overall productivity of compounds is decreased (Adams et al., 2013). However, such negative effect could be countered by applying a combination of stress factors along with the twostage strategy employed in a given life cycle in photoautotrophic, heterotrophic, or mixotrophic condition. High light, nitrogen deficiency and high salinity could influence the production of lipids and carotenoids within one life cycle if biphasic strategies are followed with attenuated physio-chemical factors employed. It is clear that different strains of microalgae respond differently to several environmental stress factors (Table 1). Based on the literature reviewed it is understood that nitrogen deficiency will results in accumulation of higher lipid content where as salinity impacts positively the fatty acid profile and carotenoids production in diverse microalgal species.

Simultaneous production of lipids, biomass, and carotenoids may be achieved through two phase process where growth medium rich in nitrogen and phosphates in first phase for attaining higher biomass and in second phase post late log stage high salinity and high light intensity can further enhance the production of net lipids and carotenoids. The adoption of above strategies in closed systems could achieve economically 
sustainable process. These strategies can increase the total productivity of the metabolites and lipids in the same biomass obtained at the end of growth cycle. The exact combination of different stress factors may vary with the species drawn from different climatic conditions. To date this concept of simultaneous production of lipids and carotenoids from one life cycle and two stage process by employing several rate limiting factors have not been fully explored and needs to be pursued emphatically in future.

\section{CONCLUSIONS}

Recent advances in biotechnology have created opportunities for the production of high value added metabolites with unique benefits in various industrial sectors. The laboratory scale microalgal cultivation elaborated within this review provides insight into the feasibility of carrying out autotrophic and heterotrophic processes under environmental stresses. Microalgae cultivation alone under heterotrophic conditions could not sustain biofuel and carotenoid production with current cultivation strategies. It is predicted that adoption of heterotrophy alone for microalgal growth is very problematic and cost intensive. Perhaps, combining heterotrophic-autotrophic two stage cultivation of microalgae will yield a product that would make the process economically sustainable. The cultivation conditions outlined are based on the experimental data of known microalgae but in principle could also be applicable for the developing strains by use of genetic engineering.

This study defines many favorable stress factors those influence the production of lipids and carotenoids. Microalgae, under optimal conditions, demonstrate a significant potential to produce multiple metabolites, many of which can be produced simultaneously in one growth cycle. Exploring biodiversity and selecting potential strains that produce the desired multiple products with maximum efficiency can pave the way to implement the biorefinery approach cost-effectively. Genetic manipulation of promising organisms can lead to higher commercial returns from the strains chosen on the basis of their physiological performance. The biorefinery approach provides

\section{REFERENCES}

Abalde, J., Fabregas, J., and Herrero, C. (1991). $\beta$-Carotene, vitamin C and vitamin E content of the marine microalga Dunaliella tertiolecta cultured with different nitrogen sources. Bioresour. Technol. 38, 121-125. doi: 10.1016/09608524(91)90142-7

Abe, K., Hattori, H., and Hirano, M. (2007). Accumulation and antioxidant activity of secondary carotenoids in the aerial microalga Coelastrella striolata var. multistriata. Food Chem. 100, 656-661. doi: 10.1016/j.foodchem.2005.10.026

Abed, R. M. M., Dobretsov, S., and Sudesh, K. (2009). Applications of cyanobacteria in biotechnology. J. Appl. Microbiol. 106, 1-12. doi: 10.1111/j.1365-2672.2008.03918.x

Adams, C., Godfrey, V., Wahlen, B., Seefeldt, L., and Bugbee, B. (2013). Understanding precision nitrogen stress to optimize the growth and lipid content tradeoff in oleaginous green microalgae. Bioresour. Technol. 131, 188-194. doi: 10.1016/j.biortech.2012.12.143

Aflalo, C., Meshulam, Y., Zarka, A., and Boussiba, S. (2007). On the relative efficiency of two- vs. one-stage production of astaxanthin by the new insights into the feasibility of cost-effective and continuous production of lipids and bioactive compounds from one growth cycle and possibly the two-stage cultivation process under altered physico-chemical conditions. The advantage of using culturable biological resources instead of refining the finite stocks of crude oil is that the processes will only get better with time and will lead to better economics and efficiency in tune with the growing human needs.

Microalgal biorefinery process is still in the early stage development and more focus is needed about extraction and purification of multiple products besides lipids and carotenoids from the same biomass. Therefore, more and consistent research efforts are needed to understand the trade-offs between the lipid and carotenoids production and identifying most useful metabolic engineering strategies under optimized conditions to develop better equipped biorefinery approaches. Hopefully, this review will provide a new insights in development of different cultivation strategies for enhancement of biomass rich in lipids and carotenoids using combination of stress factors in diverse microalgal strains.

\section{AUTHOR CONTRIBUTIONS}

Manuscript preparation: AM and AA. Manuscript improvement: AA, CB, Bhavdish N. Johri, Yateendra Joshi, Shivani Srivastava and $\mathrm{PH}$.

\section{ACKNOWLEDGMENTS}

The authors were immensely helped by the support provided by the Director General Dr R K Pachauri (TERI) and Vice Chancellor Dr Jane Dan Hollander (Deakin University) is also gratefully acknowledged. The critical but constructive suggestions made by Prof. BN Johri on an earlier draft were particularly useful. AKM duly acknowledges the financial support provided by Deakin University in the form of a doctoral fellowship. Last but not the least, copy editing of the entire manuscript carried out by Mr. Yateendra Joshi and Dr. Shivani Srivastava is thankfully acknowledged. green alga Haematococcus pluvialis. Biotechnol. Bioeng. 98, 300-305. doi: 10.1002/bit.21391

Azachi, M., Sadka, A., Fisher, M., Goldshlag, P., Gokhman, I., and Zamir, A. (2002). Salt induction of fatty acid elongase and membrane lipid modifications in the extreme halotolerant alga Dunaliella salina. Plant Physiol. 129, 1320-1329. doi: 10.1104/pp.001909

Azma, M., Mohamed, M. S., Mohomad, R., Rahim, R. A., and Ariff, A. B. (2011). Improvement of medium composition for heterotrophic cultivation of green microalgae, Tetraselmis suecica, using response surface methodology. Biochem. Eng. J. 53, 187-195. doi: 10.1016/j.bej.2010.10.010

Bartley, M. L., Boeing, W. J., Corcoran, A. A., Holguin, F. O., and Schaub, T. (2013). Effects of salinity on growth and lipid accumulation of biofuel microalga Nannochloropsis salina and invading organisms. Biomass Bioenerg. 54, 83-88. doi: 10.1016/j.biombioe.2013.03.026

Belotti, G., Caprariis, B. D., Filippis, P. D., Scarsella, M., and Verdone, N. (2014). Effect of Chlorella vulgaris growing conditions on bio-oil production via fast pyrolysis. Biomass Bioenerg. 61, 187-195. doi: 10.1016/j.biombioe.2013. 12.011 
Ben-Amotz, A. (2004). "Industrial production ofmicroalgal cell-mass and secondary products, major industrial species, Dunaliella," in Handbook of Microalgal Culture Biotechnology and Applied Phycology, ed A. Richmond (Oxford: Blackwell Publishing Ltd), 273-280.

Borowitzka, M. A. (2013). High-value products from microalgae: their development and commercialization. J. App. Phycol. 25, 743-756. doi: 10.1007/s10811-013-9983-9

Borowitzka, M. A., Huisman, J. M., and Osborn, A. (1991). Culture of the astaxanthin-producing green alga Haematococcus pluvialis 1. Effects of nutrients on growth and cell type. J. Appl. Phycol. 3, 295-304. doi: 10.1007/BF00026091

Boussiba, S., and Vonshak, A. (1991). Astaxanthin accumulation in the green alga Haematococcus pluvialis 1. Plant Cell Physiol. 32, 1077-1082.

Boyle, N. R., and Morgan, J. A. (2009). Flux balance analysis of primary metabolism in Chlamydomonas reinhardtii. BMC Syst. Biol. 3:4. doi: 10.1186/1752-0509-3-4

Cai, M., Li, Z., and Qi, A. (2009). Effects of iron electrovalence and species on growth and astaxanthin production of Haematococcus pluvialis. Chin. J. Oceanol. Limnol. 27, 370-375. doi: 10.1007/s00343-009-9176-1

Campenni, L., Nobre, B. P., Santos, C. A., Oliveira, A. C., Aires-Barros, A. R., Palavra, A. M., et al. (2013). Carotenoids and lipids production of autotrophic microalga Chlorella protothecoides under nutritional, salinity and luminosity stress conditions. Appl. Microbiol. Biotechnol. 97, 1383-1393. doi: 10.1007/s00253-012-4570-6

Cerón, M. C., García-Malea, M. C., Rivas, J., Acien, F. G., Fernandez, J. M., Del Río, E., et al. (2007). Antioxidant activity of Haematococcus pluvialis cells grown in continuous culture as a function of their carotenoid and fatty acid content. Appl. Microbiol. Biotechnol. 74, 1112-1119. doi: 10.1007/s00253-006-0743-5

Cerón-García, M. C., Macías-Sánchez, M. D., Sánchez-Mirón, A., GarcíaCamacho, F., and Molina-Grima, E. (2013). A process for biodiesel production involving the heterotrophic fermentation of Chlorella protothecoides with glycerol as the carbon source. Appl. Energy 103, 341-349. doi: 10.1016/j.apenergy.2012.09.054

Chacon-Lee, T. L., and Gonzalez-Marino, G. E. (2010). Microalgae for healthy foods: possibilities and challenges. Comprehensive Rev. Food Sci. Food Safety 9, 655-675. doi: 10.1111/j.1541-4337.2010.00132.x

Chekanov, K., Lobakova, E., Selyakh, I., Semenova, L., Sidorov, R., and Solovchenko, A. (2014). Accumulation of astaxanthin by a new Haematococcus pluvialis strain BM1 from the White Sea coastal rocks (Russia). Mar. Drugs 12, 4504-4520. doi: 10.3390/md12084504

Chen, C. Y., Yeh, K. L., Aisyah, R., Lee, D. J., and Chang, J. S. (2011). Cultivation, photobioreactor design and harvesting of microalgae for biodiesel production: a critical review. Bioresour. Technol. 102, 71-81. doi: 10.1016/j.biortech.2010.06.159

Chen, G. Q., and Chen, F. (2006). Growing phototrophic cells without light. Biotechnol. Lett. 28, 607-616. doi: 10.1007/s10529-006-0025-4

Cheng, D., and He, Q. (2014). Assessment of environmental stresses for enhanced microalgal biofuel production - an overview. Front. Energy Res. 2:26. doi: $10.3389 /$ fenrg. 2014.00026

Christaki, E., Bonos, E., Giannenas, I., and Florou-Paneri, P. (2013). Functional properties of carotenoids originating from algae. J. Sci. Food Agric. 93, 5-11. doi: $10.1002 /$ jsfa.5902

Clarens, A., Resurreccion, E., White, M., and Colosi, L. (2010). Environmental life cycle comparison of algae to other bioenergy feedstocks. Environ. Sci. Technol. 44, 1813-1819. doi: 10.1021/es902838n

Coesel, S. N., Baumgartner, A. C., Teles, L. M., Ramos, A. A, Henriques, N. M., Cancela, L., et al. (2008). Nutrient limitation is the main regulatory factor for carotenoid accumulation and for Psy and Pds steady state transcript levels in Dunaliella salina (Chlorophyta) exposed to high light and salt stress. Mar. Biotechnol. 10, 602-611. doi: 10.1007/s10126-008-9100-2

Converti, A., Casazza, A. A., Ortiz, E. Y., Perego, P., and Borghi, M. D. (2009). Effect of temperature and nitrogen concentration on the growth and lipid content of Nannochloropsis oculata and Chlorella vulgaris for biodiesel production. Chem. Eng. Prog. Process Intensification 48, 1146-1151. doi: 10.1016/j.cep.2009.03.006

Cordero, B. F., Couso, I., León, R., Rodríguez, H., and Vargas, M. A. (2011). Enhancement of carotenoids biosynthesis in Chlamydomonas reinhardtii by nuclear transformation using a phytoene synthase gene isolated from Chlorella zofingiensis. Appl. Microbiol. Biotechnol. 91, 341-351. doi: 10.1007/s00253-0113262-y

Del Campo, J. A., Morenom, J., Rodríguezm, H., Vargasm, M. A., Rivasm, J., and Guerrero, M. G. (2000). Carotenoid content of chlorophycean microalgae. Factors determining lutein accumulation in Muriellopsis sp. (Chlorophyta). J. Biotechnol. 76, 51-59. doi: 10.1016/S0168-1656(99)00178-9

Del Campo, J. A., Rodríguez, H., Moreno, J., Vargas, M. A., Rivas, J., and Guerrero, M. G. (2004). Accumulation of astaxanthin and lutein in Chlorella zofingiensis (Chlorophyta). App. Microbiol. Biotechnol. 64, 848-854. doi: 10.1007/s00253003-1510-5

Del Campo, J. A., García-González, M., and Guerrero, M. G. (2007). Outdoor cultivation of microalgae for carotenoid production: current state and perspectives. Appl. Microbiol. Biotechnol. 74, 1163-1174. doi: 10.1007/s00253007-0844-9

Demming-Adams, B., Adams, W. W. III. (2002). Antioxidants in photosynthesis nutrition. Science 298, 2149-2153. doi: 10.1126/science.1078002

De Swaaf, M. E., Sijtsma, L., and Pronk, J. T. (2003). High-cell-density fed-batch cultivation of the docosahexaenoic acid producing marine alga Crypthecodinium cohnii. Biotechnol. Bioeng. 81, 666-672. doi: 10.1002/bit.10513

Domínguez-Bocanegra, A. R., Guerrero Legarreta, I., Martinez Jeronimo, F., and Tomasini Campocosio, A. (2004). Influence of environmental and nutritional factors in the production of astaxanthin from Haematococcus pluvialis. Bioresour. Technol. 92, 209-214. doi: 10.1016/j.biortech.2003.04.001

Dunahay, T. G., Jarvis, E. E., Dais, S. S., and Roessler, P. G. (1996). Manipulation of microalgal lipid production using genetic engineering. Appl. Biochem. Biotechnol. 57, 223-231. doi: 10.1007/BF02941703

El-Baky, H. H. A., El-Baz, F. K., and El-Baroty, G. S. (2004). Production of antioxidant by the green alga Dunaliella salina. Int. J. Agri. Biol. 6, 49-57.

El-Baz, F. K., Aboul-Enein, M. A., El-Baroty, G. S., Youssef, A. M., and Abd ElBaky, H. H. (2002). Accumulation of antioxidant vitamins in Dunaliella salina. Online J. Biol. Sci. 2, 220-223. doi: 10.3923/jbs.2002.220.223

Eonseon, J., Polle, J. W., Lee, H. K., Hyun, S. M., and Chang, M. J. (2003). Xanthophylls in microalgae: from biosynthesis to biotechnological mass production and application. J. Microbial. Biotechnol. 13, 165-174.

Fan, J., Cui, Y., Wan, M., Wang, W., and Li, Y. (2014). Lipid accumulation and biosynthesis genes response of the oleaginous Chlorella pyrenoidosa under three nutrition stressors. Biotechnol. Biofuels 7:17. doi: 10.1186/1754-6834-7-17

Feng, F. Y., Yang, W., Jiang, G. Z., Xu, Y. N., and Kuang, T. Y. (2005). Enhancement of fatty acid production of Chlorella sp. (Chlorophyceae) by addition of glucose and sodium thiosulphate to culture medium. Process Biochem. 40, 1315-1318. doi: 10.1016/j.procbio.2004.06.011

Feng, P., Deng, Z., Fan, L., and Hu, Z. (2012). Lipid accumulation and growth characteristics of Chlorella zofingiensis under different nitrate and phosphate concentrations. J. Biosci. Bioeng. 114, 405-410. doi: 10.1016/j.jbiosc.2012.05.007

Fernández-Sevilla, J. M., Fernandez, F. G. A., and Grima, E. M. (2010). Biotechnological production of lutein and its applications. Appl. Microbiol. Biotechnol. 86, 27-40. doi: 10.1007/s00253-009-2420-y

Fraeye, I., Bruneel, C., Lemahieu, C., Buyse, J., Muylaert, K., and Foubert, I. (2012). Dietary enrichment of eggs with omega-3 fatty acids: a review. Food Res. Int. 48, 481 961-969. doi: 10.1016/j.foodres.2012.03.014

Fu, W., Guğmundsson, O., Paglia, G., Herjólfsson, G., Andrésson, O. S., Palsson, B., et al. (2013). Enhancement of carotenoid biosynthesis in the green microalga Dunaliella salina with light-emitting diodes and adaptive laboratory evolution. Appl. Microbiol. Biotechnol. 97, 2395-2403. doi: 10.1007/s00253-012-4502-5

García-González, M., Moreno, J., Manzano, C., Florencio, F. J., and Guerrero, M. G. (2005). Production of Dunaliella salina biomass rich in 9-cis $\beta$-carotene and lutein in a closed tubular photobioreactor. J. Biotechnol. 115, 81-90. doi: 10.1016/j.jbiotec.2004.07.010

García-Malea, M. C., Acié, F. G., Del Río, E., Fernández, J. M., Cerón, M. C., Guerrero, M. G., et al. (2009). Production of astaxanthin by Haematococcus pluvialis: taking the one-step system outdoors. Biotechnol. Bioeng. 102, 651-657. doi: 10.1002/bit.22076

Gimpel, J. A., Henríquez, V., and Mayfield, S. P. (2015). In metabolic engineering of eukaryotic microalgae: potential and challenges come with great diversity. Front. Microbiol. 6:1376. doi: 10.3389/fmicb.2015. 01376 
Gómez, P. 1., and González, M. A. (2005). The effect of temperature and irradiance on the growth and carotenogenic capacity of seven strains of Dunaliella salina (Chlorophyta) cultivated under laboratory conditions. Biol. Res. 38, 151-162. doi: 10.4067/S0716-97602005000200005

Gomez, P. I., Barriga, A., Cifuentes, A. S., and Gonzalez, M. A. (2003). Effect of salinity on the quantity and quality of carotenoids accumulated by Dunaliella salina (strain CONC-007) and Dunaliella bardawil (strain ATCC 30861) Chlorophyta. Biol. Res. 36, 185-192. doi: 10.4067/S0716-97602003000200008

Gonçalves, A., Pires, J., and Simões, M. (2013). Lipid production of Chlorella vulgaris and Pseudokirchneriella subcapitata. Int. J. Energy Environ. Eng. 4, 1-6. doi: 10.1186/2251-6832-4-14

González, L. E., Díaz, G. C., Aranda, D. A. G., Cruz, Y. R., and Fortes, M. M. (2015). Biodiesel production based in microalgae: a biorefinery approach. Nat. Sci. 7, 358-369. doi: 10.4236/ns.2015.77039

González-Fernández, C., Sialve, B., Bernet, N., and Steyer, J. P. (2012). Impact of micro-algae characteristics on their conversion to biofuel. Part II: focus on biomethane production. Biofuels Bioprod. Biorefining 6, 205-218. doi: $10.1002 / \mathrm{bbb} .337$

Gouveia, L. (2014). From tiny microalgae to huge biorefineries. Oceanography 2:120. doi: $10.4172 / 2332-2632.1000120$

Griffiths, M., and Harrison, S. (2009). Lipid productivity as a key characteristic for choosing algal species for biodiesel production. J. Appl. Phycol. 21, 493-507. doi: 10.1007/s10811-008-9392-7

Grossman, A. R., Bhaya, D., Apt, K. E., and Kehoe, D. M. (1995). Light-harvesting complexes in oxygenic photosynthesis: diversity, control, and evolution. Annu. Rev. Genet. 29, 231-288. doi: 10.1146/annurev.ge.29.120195.001311

Grünewald, K., Hirschberg, J., and Hagen, C. (2001). Ketocarotenoid biosynthesis outside of plastids in the unicellular green alga Haematococcus pluvialis. J. Biol. Chem. 276, 6023-6029. doi: 10.1074/jbc.M006400200

Guedes, A. C., Amaro, H. M., and Malcata, F. X. (2011). Microalgae as sources of carotenoids. Mar. Drugs 9, 625-644. doi: 10.3390/md9040625

Guerin, M., Huntley, M. E., and Olaizola, M. (2003). Haematococcus astaxanthin: applications for human health and nutrition. Trends Biotechnol. 21, 210-216. doi: 10.1016/S0167-7799(03)00078-7

Hadi, M. R., Shariati, M., and Afsharzadeh, S. (2008). Microalgal biotechnology: carotenoid and glycerol production by the green algae Dunaliella isolated from the Gave-Khooni salt marsh, Iran. Biotechnol. Bioprocess Eng. 13, 540-544. doi: 10.1007/s12257-007-0185-7

Han, D., Li, Y., and Hu, Q. (2013). Astaxanthin in microalgae: pathways, functions and biotechnological implications. Algae 28, 131-147. doi: 10.4490/algae.2013.28.2.131

Hannon, M., Gimpel, J., Tran, M., Rasala, B., and Mayfield, S. (2010). Biofuels from algae: challenges and potential. Biofuels 1, 763-784. doi: 10.4155/bfs.10.44

He, P., Duncan, J., and Barber, J. (2007). Astaxanthin accumulation in the green alga Haematococcus pluvialis: effects of cultivation parameters. J. Integr. Plant Biol. 49, 447-451. doi: 10.1111/j.1744-7909.2007.00468.x

Heredia-Arroyo, T., Wei, W., and Hu, B. (2010). Oil accumulation via heterotrophic/mixotrophic Chlorella protothecoides. Appl. Biochem. Biotechnol. 162, 1978-1995. doi: 10.1007/s12010-010-8974-4

Hildebrand, M. (2005). Cloning and functional characterization of ammonium transporters from the marine diatom Cylindrotheca fusiformis (Bacillariophyceae) 1. J. Phycol. 41, 105-113. doi: 10.1111/j.1529-8817.2005.04108.x

Hirschberg, J., Cohen, M., Harker, M., Lotan, T., Mann, V., and Pecker, I. (1997). Molecular genetics of the carotenoid biosynthesis pathway in plants and algae. Pure Appl. Chem. 69, 2151-2158. doi: 10.1351/pac199769102151

Ho, S. H., Chen, C. N. N., Lai, Y. Y., Lu, W. B., and Chang, J. S. (2014a). Exploring the high lipid production potential of a thermotolerant microalga using statistical optimization and semi-continuous cultivation. Bioresour. Technol. 163, 128-135. doi: 10.1016/j.biortech.2014.04.028

Ho, S. H., Chen, C. Y., and Chang, J. S. (2012). Effect of light intensity and nitrogen starvation on $\mathrm{CO}_{2}$ fixation and lipid/carbohydrate production of an indigenous microalgae Scenedesmus obliquus CNW-N. Bioresour. Technol. 113, 244-252. doi: 10.1016/j.biortech.2011.11.133

Ho, S. H., Nakanishi, A., Ye, X., Chang, J. S., Hara, K., Hasunuma, T., et al. (2014b). Optimizing biodiesel production in marine Chlamydomonas sp. JSC4 through metabolic profiling and an innovative salinity-gradient strategy. Biotechnol. Biofuels 7:97. doi: 10.1186/1754-6834-7-97
Hu, H., and Gao, K. (2003). Optimization of growth and fatty acid composition of a unicellular marine picoplankton, Nannochloropsis sp. with enriched carbon sources. Biotechnol. Lett. 25, 421-425. doi: 10.1023/A:1022489108980

$\mathrm{Hu}$, Q. (2004). "Environmental effects on cell composition," in Handbook of Microalgal Culture, ed A.Richmond (Oxford: Blackwell), 83-93.

Hu, Q., Sommerfeld, M., Jarvis, E., Ghirardi, M., Posewitz, M., Seibert, M., et al. (2008). Microalgal triacylglycerols as feedstocks for biofuel production: perspectives and advances. Plant J. 54, 621-639. doi: 10.1111/j.1365313X.2008.03492.x

Hu, Q., Zhang, C. W., and Sommerfeld, M. (2006). "Biodiesel from algae: lessons learned over the past 60 years and future perspectives," in Annual Meeting of the Phycological Society of America (Juneau), 0-41 (Abstract).

Imamoglu, E., Dalay, M. C., and Sukan, F. V. (2009). Influence of different stress media and high light intensities on accumulation of astaxanthin in green alga Haematococcus pluvialis. New Biotechnol. 26, 199-204. doi: 10.1016/j.nbt.2009.08.007

Ip, P. F., Won, K. H., and Chen, F. (2004). Enhanced production of astaxanthin by the green microalga Chlorella zofingiensis in mixotrophic culture. Proc. Biochem. 39, 1761-1766. doi: 10.1016/j.procbio.2003.08.003

Jacob-Lopes, E., Ramírez Mérida, L. G., Queiroz, M. I., and Zepka, L. Q. (2015). Microalgal Biorefineries, Biomass Production and Uses, Mr. Ehsan Atazadeh (Ed.).

Jacob-Lopes, E., Zepka, L. Q., and Queiroz, M. I. (2014). "Cyanobacteria and carbon sequestration," in Cyanobacteria An Economic Perspective, eds N. Sharma, A. Rai, and L. Stal (Chichester: Wiley Blackwell), 65-71.

James, G. O., Hocart, C. H., Hillier, W., Price, G. D., and Djordjevic, M. A. (2013). Temperature modulation of fatty acid profiles for biofuel production in nitrogen deprived Chlamydomonas reinhardtii. Bioresour. Technol. 127, 441-447. doi: 10.1016/j.biortech.2012.09.090

Ji, C.-F., Yu, X.-J., Chen, Z.-A., Xue, S., Legrand, J., and Zhang, W. (2011). Effects of nutrient deprivation on biochemical compositions and photohydrogen production of Tetraselmis subcordiformis. Int. J. Hydrogen Energy 36, 5817-5821. doi: 10.1016/j.ijhydene.2010.12.138

Jiang, H., and Gao, K. (2004). Effects of lowering temperature during culture on the production of polyunsaturated fatty acids in the marine diatom Phaeodactylum tricornutum. J. Phycol. 40, 651-654. doi: 10.1111/j.1529-8817.2004.03112.x

Jiménez, C., and Niell, F. X. (1991). Growth of Dunaliella viridis Teodoresco: effect of salinity, temperature and nitrogen concentration. J. Appl. Phycol. 3, 319-327. doi: 10.1007/BF02392885

Johnson, X., and Alric, J. (2013). Central carbon metabolism and electron transport in Chlamydomonas reinhardtii: metabolic constraints for carbon partitioning between oil and starch. Eukaryot. Cell 12, 776-793. doi: 10.1128/EC. 00318-12

Juneja, A., Ceballos, R. M., and Murthy, G. S. (2013). Effects of environmental factors and nutrient availability on the biochemical composition of algae for biofuels production: a review. Energies 6, 4607-4638. doi: 10.3390/en60 94607

Kalacheva, G. S., Zhila, N. O., Volova, T. G. (2002). Lipid and hydrocarbon compositions of a collection strain and a wild sample of the green microalga Botryococcus. Aquatic Ecol. 36, 317-331. doi: 10.1023/A:1015615618420

Kaplan, D., Richmond, A. E., Dubinsky, Z., and Aaronson, S. (1986). "Algal nutrition," in Handbook for Microalgal Mass Culture, ed A. Richmond (Boca Raton, FL: CRC Press), 147-198.

Khoeyi, Z. A., Seyfabadi, J., and Ramezanpour, Z. (2012). Effect of light intensity and photoperiod on biomass and fatty acid composition of the microalgae, Chlorella vulgaris. Aquac. Int. 20, 41-49. doi: 10.1007/s10499-0119440-1

Khotimchenko, S. V., and Yakovleva, I. M. (2005). Lipid composition of the red alga Tichocarpus crinitus exposed to different levels of photon irradiance. Phytochemistry 66, 73-79. doi: 10.1016/j.phytochem.2004.10.024

Kobayashi, M., Kakizono, T., and Nagai, S. (1993). Enhanced carotenoid biosynthesis by oxidative stress in acetate-induced cyst cells of a green unicellular alga, Haematococcus pluvialis. Appl. Environ. Microbiol. 59, 867-873.

Kobayashi, M., Kakizono, T., Yamaguchi, K., Nishio, N., and Nagai, S. (1992). Growth and astaxanthin formation of Haematococcus pluvialis in heterotrophic and mixotrophic condition. J. Ferment. Bioeng. 74, 17-20. doi: 10.1016/0922$338 \mathrm{X}(92) 90261-\mathrm{R}$ 
Kong, W., Song, H., Cao, Y., Yang, H. S., Hua, S., and Xia, C. (2011). The characteristics of biomass production, lipid accumulation and chlorophyll biosynthesis of Chlorella vulgaris under mixotrophic cultivation. Afr. J. Biotechnol. 10, 11620-11630. doi: 10.5897/AJB11.617

Kong, W., Yang, H., Cao, Y., Song, H., Hua, S., and Xia, C. (2013). Effects of glycerol and glucose on the enhancement of biomass, lipid and soluble carbohydrate production by Chlorella vulgaris in mixotrophic culture. Food Technol. Biotechnol. 51, 62-69.

Kovacic, P. (1986). Review of free radicals in biology and medicine Barry Halliwell and John M. C. Gutteridge. The Clarendon Press, Oxford University Press, New York, NY 10016. J. Pharm. Sci. 75, 105-106. doi: 10.1002/jps. 2600750133

Lamers, P. P., Janssen, M., De Vos, R. C. H., Bino, R. J., and Wijffels, R. H. (2012). Carotenoid and fatty acid metabolism in nitrogen-starved Dunaliella salina, a unicellular green microalga. J. Biotechnol. 162, 21-27. doi: 10.1016/j.jbiotec.2012.04.018

Lamers, P. P., van de Laak, C. C., Kaasenbrood, P. S., Lorier, J., Janssen, M., De Vos, R. C., et al. (2010). Carotenoid and fatty acid metabolism in light-stressed Dunaliella salina. Biotechnol. Bioeng. 106, 638-648. doi: 10.1002/bit.22725

Leesing, R., Kookkhunthod, S., and Nontaso, N. (2011). Microalgal lipid production by microalga Chlorella sp. KKU-S2. Eng. Technol. 52, 499-502.

Lemoine, Y., and Schoefs, B. (2010). Secondary ketocarotenoid astaxanthin biosynthesis in algae: a multifunctional response to stress. Photosynth Res. 106, 155-177. doi: 10.1007/s11120-010-9583-3

Li, X., Hu, H. Y., Gan, K., and Sun, Y. X. (2010). Effects of different nitrogen and phosphorus concentrations on the growth, nutrient uptake, and lipid accumulation of a freshwater microalga Scenedesmus sp. Bioresour. Technol. 101, 5494-5500. doi: 10.1016/j.biortech.2010.02.016

Li, Y., Horsman, M., Wu, N., Lan, C. Q., and Dubois-Calero, N. (2008). Biofuels from microalgae. Biotechnol. Prog. 24, 815-820. doi: 10.1021/bp070371k

Li, Z., Sun, M., Li, Q., Li, A., and Zhang, C. (2012). Profiling of carotenoids in six microalgae (Eustigmatophyceae) and assessment of their $\beta$-carotene productions in bubble column photobioreactor. Biotechnol. Lett. 34, 2049-2053. doi: 10.1007/s10529-012-0996-2

Liu, J., Yuan, C., Hu, G., and Li, F. (2012). Effects of light intensity on the growth and lipid accumulation of microalga Scenedesmus sp. 11-1 under nitrogen limitation. Appl. Biochem. Biotechnol. 166, 2127-2137. doi: 10.1007/s12010012-9639-2

Liu, X. J., Jiang, Y., and Chen, F. (2005). Fatty acid profile of the edible filamentous cyanobacterium Nostoc flagelliforme at different temperatures and developmental stages in liquid suspension culture. Proc. Biochem. 40, 371-377. doi: 10.1016/j.procbio.2004.01.018

MacColl, R. (1998). Cyanobacterial phycobilisomes. J. Struct. Biol. 124, 311-334. doi: 10.1006/jsbi.1998.4062

Markou, G., Chatzipavlidis, I., and Georgakakis, D. (2012). Carbohydrates production and bio-flocculation characteristics in cultures of Arthrospira (Spirulina) platensis: improvements through phosphorus limitation process. Bioenerg. Res. 5, 915-925. doi: 10.1007/s12155-012-9205-3

Markou, G., and Nerantzis, E. (2013). Microalgae for high-value compounds and biofuels production: a review with focus on cultivation under stress conditions. Biotechnol. Adv. 8, 1532-1542. doi: 10.1016/j.biotechadv.2013. 07.011

Martinez-Roldan, A. J., Perales-Vela, H. V., Canizares-Villanueva, R. O., and Torzillo, G. (2014). Physiological response of Nannochloropsis sp. to saline stress in laboratory batch cultures. J. Appl. Phycol. 26, 115-121. doi: 10.1007/s10811-013-0060-1

Mata, T. M., Martins, A. A., and Caetano, N. S. (2010). Microalgae for biodiesel production and other applications: a review. Renew. Sust. Energy Rev. 14, 217-232. doi: 10.1016/j.rser.2009.07.020

Miao, X. L., and Wu, Q. Y. (2006). Biodiesel production from heterotrophic microalgal oil. Bioresour. Technol. 97, 841-846. doi: 10.1016/j.biortech.2005.04.008

Mishra, A., Mandoli, A., and Jha, B. (2008). Physiological characterization and stress-induced metabolic responses of Dunaliella salina isolated from salt pan. J. Ind. Microbiol. Biotechnol. 35, 1093-1101. doi: 10.1007/s10295-008-0387-9

Moellering, E. R., and Benning, C. (2010). RNA interference silencing of a major lipid droplet protein affects lipid droplet size in Chlamydomonas reinhardtii. Eukaryot. Cell 9, 97-106. doi: 10.1128/EC.00203-09
Morris, I. (1974). "Nitrogen assimilation and protein synthesis," in Algal Physiology and Biochemistry, ed. W. D. P. Stewart (Oxford: Blackwell), 583-609.

Mujtaba, G., Choi, W., Lee, C.-G, and Lee, K. (2012). Lipid production by Chlorella vulgaris after a shift from nutrient-rich to nitrogen starvation conditions. Bioresour. Technol. 123, 279-283. doi: 10.1016/j.biortech.2012.07.057

Mulders, K. J. M., Lamers, P. P., Martens, D. E., and Wijffels, R. H. (2014). Phototrophic pigment production with microalgae: biological constraints and opportunities. J. Phycol. 50, 229-242. doi: 10.1111/jpy.12173

Neilson, A. H., and Larsson, T. (1980). The utilization of organic nitrogen for growth of algae: physiological aspects. Physiol. Plantarum. 48, 542-553. doi: 10.1111/j.1399-3054.1980.tb03302.x

Niu, Y. F., Zhang, M. H., Li, D. W., Yang, W. D., Liu, J. S., Bai, W. B., et al. (2013). Improvement of neutral lipid and polyunsaturated fatty acid biosynthesis by overexpressing a type 2 diacylglycerol acyltransferase in marine diatom Phaeodactylum tricornutum. Mar. Drugs 11, 4558-4569. doi: $10.3390 / \mathrm{md} 11114558$

Nobre, B. P., Villalobos, F., Barrágan, B. E., Oliveira, A. C., Batista, A. P., Marques, P. A. S. S., et al. (2013). A biorefinery from Nannochloropsis sp. microalga Extraction of oils and pigments. Production of biohydrogen from the leftover biomass. Bioresour. Technol. 135, 128-136. doi: 10.1016/j.biortech.2012. 11.084

Norsker, N.-H, Barbosa, M. J., Vermuë, M. H, and Wijffels, R. H. (2011). Microalgal production-a clook at the economics. Biotechnol. Adv. 29, 24-27. doi: 10.1016/j.biotechadv.2010.08.005

Ogbonda, K. H., Aminigo, R. E., and Abu, G. O. (2007). Influence of temperature and $\mathrm{pH}$ on biomass production and protein biosynthesis in a putative Spirulina sp. Bioresour. Technol. 98, 2207-2211. doi: 10.1016/j.biortech.2006.08.028

Oh-Hama, T., and Miyachi, S. (1992). "Chlorella," in Microalgal Biotechnology, eds M. A. Borowitzka and L. J. Borowitzka (Cambridge University Press, Cambridge, UK), 3-26.

Orosa, M., Torres, E., Fidalgo, P., and Abalde, J. (2000). Production and analysis of secondary carotenoids in green algae. J. Appl. Phycol. 12, 553-556. doi: 10.1023/A:1008173807143

Orosa, M., Valero, J. F., Herrero, C., and Abalde, J. (2001). Comparison of the accumulation of astaxanthin in Haematococcus pluvialis and other green microalgae under N-starvation and high light conditions. Biotech. Lett. 23, 1079-1085. doi: 10.1023/A:1010510508384

Pal, D., Khozin-Goldberg, I., Cohen, Z., and Boussiba, S. (2011). The effect of light, salinity, and nitrogen availability on lipid production by Nannochloropsis sp. Appl. Microbiol. Biotechnol. 90, 1429-1441. doi: 10.1007/s00253-011-3170-1

Peng, J., Yin, K., Yuan, J. P., Cao, G. X., Xue, M., Wu, C. F., et al. (2012). Characterization of a newly isolated green microalga Scenedesmus sp. as a potential source of biodiesel. Afr. J. Biotechnol. 11, 16083-16094. doi: 10.5897/AJB12.1319

Perez-Garcia, O. I., Escalante, F. M., de-Bashan, L. E., and Bashan, Y. (2011). Heterotrophic cultures of microalgae: metabolism and potential products. Water Res. 45, 11-36. doi: 10.1016/j.watres.2010.08.037

Pick, U. (2002). "Adaptation of the halotolerant alga Dunaliella to high salinity," in Salinity: Environment - Plants - Molecules, eds A. Läuchli and U. Lüttge (Berlin: Springer), 97-112.

Polle, J. E. W., and Song, Q. (2009). "Development of genetics and molecular tool kits for species of the unicellular green alga Dunaliella (Chlorophyta)," in The Alga Dunaliella: Biodiversity, Physiology, Genomics and Biotechnology, eds M. A. Ben-Amotz, J. E. W. Polle, and D. V. Subba Rao (Einfield, NH: Science Publishers), 403-422.

Prîbyl, P., Cepák, V., and Zachleder, V. (2012). Production of lipids in 10 strains of Chlorella and Parachlorella, and enhanced lipid productivity in Chlorella vulgaris. Appl. Microbiol. Biotechnol. 94, 549-561. doi: 10.1007/s00253-0123915-5

Priyadarshani, I., and Rath, B. (2012). Commercial and industrial applications of micro algae - A review. J. Algal Biomass Utln. 3, 89-100.

Rabbani, S., Beyer, P. V., Lintig, J., Hugueney, P., and Kleinig, H. (1998). Induced $\beta$-Carotene synthesis driven by triacylglycerol deposition in the unicellular alga Dunaliella bardawil. Plant Physiol. 116, 1239-1248. doi: 10.1104/pp.116. 4.1239

Radakovits, R., Jinkerson, R. E., Darzins, A., and Posewitz, M. C. (2010). Genetic engineering of algae for enhanced biofuel production. Eukaryot. Cell. 9, 486-501. doi: 10.1128/EC.00364-09 
Ranga Rao, A., Sarada, R., and Ravishankar, G. A. (2010). Enhancement of carotenoids in green alga Botyrocccus braunii in various autotrophic media under stress conditions. Int. J. Biomed. Pharmaceut. Sci. 4, 87-92.

Raven, J., Evans, M. W., and Korb, R. (1999). The role of trace metals in photosynthetic electron transport in $\mathrm{O}_{2}$-evolving organisms. Photosynthesis Res. 60, 111-149. doi: 10.1023/A:1006282714942

Rodolfi, L., Zittelli, C., Bassi, G., Padovani, N., Biondi, G., and Tredici, M. R. (2009). Microalgae for oil: strain selection, induction of lipid synthesis and outdoor mass cultivation in a low-cost photobioreactor. Biotechnol. Bioeng. 102, 100-112. doi: 10.1002/bit.22033

Rodrigues, D., Flores, E., Barin, J., Mercadante, A., Jacob-Lopes, E., and Zepka, Q. L. (2014). Production of carotenoids from microalgae cultivated using agroindustrial wastes. Food Res. Int. 65, 144-148. doi: 10.1016/j.foodres.2014.06.037

Ruangsomboon, S. (2012). Effect of light, nutrient, cultivation time and salinity on lipid production of newly isolated strain of the green microalga, Botryococcus braunii KMITL 2. Bioresour. Technol. 109, 261-265. doi: 10.1016/j.biortech.2011.07.025

Ryu, J. Y., Song, J. Y., Lee, J. M., Jeong, S. W., Chow, W. S., Choi, S. B., et al. (2004). Glucose-induced expression of carotenoid biosynthesis genes in the dark is mediated by cytosolic pH in the cyanobacterium Synechocystis sp. PCC 6803. J. Biol. Chem. 279, 25320-25325. doi: 10.1074/jbc.M402541200

Saha, S. K., McHugh, E., Hayes, J., Moane, S., Walsh, D., and Murray, P. (2013). Effect of various stress-regulatory factors on biomass and lipid production in microalga Haematococcus pluvialis. Bioresour. Technol. 128, 118-124. doi: 10.1016/j.biortech.2012.10.049

Salama, el.-S., Kim, H. C., Abou-Shanab, R. I., Ji, M. K., Oh, Y. K., Kim, S. H., et al. (2013). Biomass, lipid content, and fatty acid composition of freshwater Chlamydomonas mexicana and Scenedesmus obliquus grown under salt stress. Bioprocess Biosyst. Eng. 36, 827-833. doi: 10.1007/s00449-013-0919-1

Sánchez, J. F., Feranadez, J. M., Acién, F. G., Rueda, A., Pérez-Parra, J., and Molina, E. (2008). Influence of culture conditions on the productivity and lutein content of the new strain Scenedesmus almeriensis. Proc. Biochem. 43, 398-405. doi: 10.1016/j.procbio.2008.01.004

San Pedro, A., González-López, C. V., Acién, F. G., and Molina-Grima, E. (2013). Marine microalgae selection and culture conditions optimization for biodiesel production. Bioresour. Technology. 134, 353-361. doi: 10.1016/j.biortech.2013.02.032

Seambiotic. Seambiotic website. (2013). Available online at: www. seambiotic.com

Semary, N. A. E. (2012). The characterisation of bioactive compounds from an Egyptian Leptolyngbya sp. strain. Ann. Microbiol. 62, 55-59. doi: 10.1007/s13213-011-0226-5

Seyfabadi, J., Ramezanpour, Z., and Khoeyi, Z. A. (2011). Protein, fatty acid, and pigment content of Chlorella vulgaris under different light regimes. J. Appl. Phycol. 23, 721-726. doi: 10.1007/s10811-010-9569-8

Shen, Y., Pei, Z., Yuan, W., and Mao, E. (2009). Effect of nitrogen and extraction method on algae lipid yield. Int. J. Agric. Biol. Eng. 2, 51-57. doi: 10.3965/j.issn.1934-6344.2009.01.051-057

Shi, X. M., Chen, F., Yuan, J. P., and Chen, H. (1997). Heterotrophic production of lutein by selected Chlorella strains. J. Appl. Phycol. 9, 445-450. doi: 10.1023/A:1007938215655

Shi, X.-M., Zhang, X.-W., and Chen, F. (2000). Heterotrophic production of biomass and lutein by Chlorella protothecoides on various nitrogen sources. Enzyme Microb Technol. 27, 312-318. doi: 10.1016/S0141-0229(00)00208-8

Shi, X., Wu, Z., and Chen, F. (2006). Kinetic modeling of lutein production by heterotrophic Chlorella at various $\mathrm{pH}$ and temperatures. Mol. Nutr. Food Res. 50, 763-768. doi: $10.1002 / \mathrm{mnfr} .200600037$

Singh, A., Nigam, P. S., and Murphy, J. D. (2011). Mechanism and challenges in commercialisation of algal biofuels. Bioresour. Technol. 102, 26-34. doi: 10.1016/j.biortech.2010.06.057

Skjånes, K., Rebours, C., and Lindblad, P. (2013). Potential for green microalgae to produce hydrogen, pharmaceuticals and other high value products in a combined process. Crit. Rev. Biotechnol. 33, 172-215. doi: 10.3109/07388551.2012.681625

Solovchenko, A. E., Khozin-Goldberg, I., Recht, L., and Boussiba, S. (2011). Stressinduced changes in optical properties, pigment and fatty acid content of Nannochloropsis sp.: implications for non-destructive assay of total fatty acids. Mar. Biotechnol. 13, 527-535. doi: 10.1007/s10126-010-9323-x
Soratana, K., and Landis, A. (2011). Evaluating industrial symbiosis and algae cultivation from a life cycle perspective. Bioresour. Technol. 102, 6892-6901. doi: 10.1016/j.biortech.2011.04.018

Spolaore, P., Joannis-Cassan, C., Duran, E., and Isambert, A. (2006). Commercial applications of microalgae. J. Biosci. Bioeng. 101, 87-96. doi: 10.1263/jbb.101.87

Stolz, P., and Obermayer, B. (2005). Manufacturing microalgae for skin care. Cosmet. Toiletries 120, 99-106.

Sun, N., Wang, Y., Li, Y. T., Huang, J. C., and Chen, F. (2008). Sugar-based growth, astaxanthin accumulation and carotenogenic transcription of heterotrophic Chlorella zofingiensis (Chlorophyta). Process Biochem. 43, 1288-1292. doi: 10.1016/j.procbio.2008.07.014

Sushchik, N. N., Kalacheva, G. S., Zhila, N. O., Gladyshev, M. I., and Volova, T. G. (2003). A temperature dependence of the intra- and extracellular fattyacid composition of green algae ad Cyanobacterium. Russ. J. Plant Physiol. 50, 374-380. doi: 10.1023/A:1023830405898

Takagi, M., Karseno, and Yoshida, T. (2006). Effect of salt concentration on intracellular accumulation of lipids and triacylglyceride in marine microalgae Dunaliella cells. J. Biosci. Bioeng. 101, 223-226. doi: 10.1263/jbb.101.223

Takaichi, S. (2011). Carotenoids in algae: distributions, biosynthesis and functions. Mar. Drugs 9, 1101-1118. doi: 10.3390/md9061101

Takaichi, S., and Mochimaru, M. (2007). Carotenoids and carotenogenesis in cyanobacteria: unique ketocarotenoids and carotenoid glycosides. Cell Mol. Life Sci. 64, 2607. doi: 10.1007/s00018-007-7190-z

Tang, H., Chen, M., Garcia, M. E., Abunasser, N., Ng, K. Y., and Salley, S. O. (2011). Culture of microalgae Chlorella minutissima for biodiesel feedstock production. Biotechnol. Bioeng. 108, 2280-2287. doi: 10.1002/bit.23160

Touchette, B. W., and Burkholder, J. M. (2000). Review of nitrogen and phosphorus metabolism in seagrasses. J. Exp. Mar. Biol. Ecol. 250, 133-167. doi: 10.1016/S0022-0981(00)00195-7

Trentacoste, E. M., Shrestha, R. P., Smith, S. R., Glé, C., Hartmann, A. C., Hildebrand, M., et al. (2013). Metabolic engineering of lipid catabolism increases microalgal lipid accumulation without compromising growth. Proc. Nat. Acad. Sci. U.S.A. 110, 19748-19753. doi: 10.1073/pnas.1309299110

Tripathi, U., Sarada, R., and Ravishankar, G. (2002). Effect of culture conditions on growth of green alga Haematococcus pluvialis and astaxanthin production. Acta Physiol. Plant. 24, 323-329. doi: 10.1007/s11738-002-0058-9

Venkatesan, S., Swamy, M. S., Jayavel, D., and Senthil, C. (2013). Effects of nitrate and phosphate on total lipid content and pigment production in Botryococcus braunii Kutzing KM-104. J. Acad. Indus. Res. 1, 820-825.

Vonshak, A., Cheung, M., and Chen, F. (2000). Mixotrophic growth modifies the response of Spirulina (Arthrospira) platensis (Cyanobacteria) cells to light. J. Phycol. 36, 675-679. doi: 10.1046/j.1529-8817.2000.99198.x

Wahidin, S., Idris, A., and Shaleh, S. R. M. (2013). The influence of light intensity and photoperiod on the growth and lipid content of microalgae Nannochloropsis sp. Bioresour. Technol. 129, 7-11. doi: 10.1016/j.biortech.2012.11.032

Wan, M., Liu, P., Xia, J., Rosenberg, J. N., Oyler, G. A., Betenbaugh, M. J., et al. (2011). The effect of mixotrophy on microalga growth, lipid content, and expression levels of three pathway genes in Chlorella sorokiniana. Appl. Microbiol. Biotechnol. 91, 835-844. doi: 10.1007/s00253-011-3399-8

Wan, M. X., Wang, R. M., Xia, J. L., Rosenberg, J. N., Nie, Z. Y., Kobayashi, N., et al. (2012). Physiological evaluation of a new Chlorella sorokiniana isolate for its biomass production and lipid accumulation in photoautotrophic and heterotrophic cultures. Biotechnol. Bioeng. 109, 1958-1964. doi: 10.1002/bit.24477

Wang, S. B., Chen, F., Sommerfeld, M., and Hu, Q. (2004). Proteomic analysis of molecular response to oxidative stress by the green alga Haematococcus pluvialis (Chlorophyceae). Planta 220, 17-29. doi: 10.1007/s00425-004-1 323-5

Wang, Y., and Peng, J. (2008). Growth-associated biosynthesis of astaxanthin in heterotrophic Chlorella zofingiensis (Chlorophyta). World J. Microbiol. Biotechnol. 24, 1915-1922. doi: 10.1007/s11274-008-9692-8

Ward, O. P., and Singh, A. (2005). Omega-3/6 fatty acids: alternative sources of production. Proc. Biochem. 40, 3627-3652. doi: 10.1016/j.procbio.2005.02.020

Wei, L., and Huang, X. (2015). Temperature effects on lipid properties of microalgae Tetraselmis subcordiformis and Nannochloropsis oculata as biofuel resources. Chin. J. Oceanol. Limnol. 33, 99-106. doi: 10.1007/s00343-015-3 346-0 
Wen, Z. Y., and Chen, F. (2001). A perfusion- cell bleeding culture strategy for enhancing the productivity of eicosapentaenoic acid by Nitzschia laevis. Appl. Microbiol. Biotechnol. 57, 316-322. doi: 10.1007/s002530100786

Wijffels, R. H., Barbosa, M. J., and Eppink, M. H. M. (2010). Microalgae for the production of bulk chemicals and biofuels. Biofuels. Bioprod. Biorefin. 4, 287-295. doi: 10.1002/bbb.215

Wu, L. F., Chen, P. C., and Lee, C. M. (2013). The effects of nitrogen sources and temperature on cell growth and lipid accumulation of microalgae. Int. Biodeterior. Biodegrad. 85, 506-510. doi: 10.1016/j.ibiod.2013.05.016

Xie, Y., Ho, S. H., Chen, C. N. N., Chen, C. Y., Ng, I. S., Jing, K. J., et al. (2013). Phototrophic cultivation of a thermo-tolerant Desmodesmus sp. for lutein production: effects of nitrate concentration, light intensity and fed-batch operation. Bioresour. Technol. 144, 435-444. doi: 10.1016/j.biortech.2013.06.064

Xin, L., Hong-ying, H., and Yu-ping, Z. (2011). Growth and lipid accumulation properties of a freshwater microalga Scenedesmus sp. under different cultivation temperature. Bioresour. Technol. 102, 3098-3102. doi: 10.1016/j.biortech.2010.10.055

Xin, L., Hu, H. Y., Ke, G., and Sun, Y. X. (2010). Effects of different nitrogen and phosphorus concentrations on the growth, nutrient uptake, and lipid accumulation of a freshwater microalga Scenedesmus sp. Bioresour. Technol. 101, 5494-5500. doi: 10.1016/j.biortech.2010.02.016

$\mathrm{Xu}, \mathrm{H} ., \mathrm{Miao}, \mathrm{X}$., and $\mathrm{Wu}, \mathrm{Q}$. (2006). High quality biodiesel production from a microalga Chlorella protothecoides by heterotrophic growth in fermenters. J. Biotechnol. 126, 499-507. doi: 10.1016/j.jbiotec.2006. 05.002

Yaakob, Z., Ali, E., Zainal, A., Mohamad, M., and Takriff, M. S. (2014). An overview: biomolecules from microalgae for animal feed and aquaculture. $J$. Biol. Res. Thessalon. 21, 6. doi: 10.1186/2241-5793-21-6

Yang, C., Hua, Q., and Shimizu, K. (2000). Energetics and carbon metabolism during growth of microalgal cells under photoautotrophic, mixotrophic and cyclic light-autotrophic/dark-heterotrophic conditions. Biochem. Eng. J. 6, 87-102. doi: 10.1016/S1369-703X(00)00080-2

Yen, H. W., Hu, I. C., Chen, C. Y., Ho, S. H., Lee, D. J., and Chang, J. S. (2013). Microalgae-based biorefinery - From biofuels to natural products. Bioresour. Technol. 135, 166-174. doi: 10.1016/j.biortech.2012.10.099
Yu, W. L., Ansari, W., Schoepp, N. G., Hannon, M. J., Mayfield, S. P., and Burkart, M. D. (2011). Modifications of the metabolic pathways of lipid and triacylglycerol production in microalgae. Microb. Cell Fact. 10:91. doi: 10.1186/1475-2859-10-91

Yuan, J. P., Peng, J., Yin, K., and Wang, J. H. (2011). Potential health-promoting effects of astaxanthin: a high-value carotenoid mostly from microalgae. Mol. Nutr. Food Res. 55, 150-165. doi: 10.1002/mnfr.201000414

Zhang, B. Y., Geng, Y. H., Li, Z. K., Hu, H. J., and Li, Y. G. (2009). Production of astaxanthin from Haematococcus in open pond by two-stage growth one-step process. Aquaculture 295, 275-281. doi: 10.1016/j.aquaculture.2009.06.043

Zhang, X., Rong, J., Chen, H., He, C., and Wang, Q. (2014). Current status and outlook in the application of microalgae in biodiesel production and environmental protection. Front. Energy Res. 2:32. doi: 10.3389/fenrg.2014.00032

Zhao, B., and Su, Y. (2014). Process effect of microalgal-carbon dioxide fixation and biomass production: a review. Renew. Sust. Ener. Rev. 31, 121-132. doi: 10.1016/j.rser.2013.11.054

Zhekisheva, M., Boussiba, S., Khozin-Goldberg, I., Zraka, A., and Cohen, Z. (2002). Accumulation of oleic acid in Haematococcus pluvialis (Chlorophyceae) under nitrogen starvation or high light is correlated with that of astaxanthin esters. J. Phycol. 38, 325-331. doi: 10.1046/j.1529-8817.2002.01107.x

Zhekisheva, M., Zarka, A., Khozin-Goldberg, I., Cohen, Z., and Boussiba, S. (2005). Inhibition of astaxanthin synthesis under high irradiance does not abolish triacylglycerol accumulation in the green alga Haematococcus pluvialis (Chlorophyceae). J. Phycol. 41, 819-826. doi: 10.1111/j.0022-3646.2005.05015.x

Conflict of Interest Statement: The authors declare that the research was conducted in the absence of any commercial or financial relationships that could be construed as a potential conflict of interest.

Copyright (c) 2016 Minhas, Hodgson, Barrow and Adholeya. This is an open-access article distributed under the terms of the Creative Commons Attribution License (CC $B Y)$. The use, distribution or reproduction in other forums is permitted, provided the original author(s) or licensor are credited and that the original publication in this journal is cited, in accordance with accepted academic practice. No use, distribution or reproduction is permitted which does not comply with these terms. 